\title{
Carcinogenicidade e mutagenicidade do malathion e seus dois análogos: uma revisão sistemática
}

\author{
Carcinogenicity and mutagenicity of malathion \\ and its two analogues: a systematic review
}

Priscilla Luna Bastos (https://orcid.org/0000-0001-5787-1542) ${ }^{1}$

Alyne Fernanda Tôrres de Lima Bastos (https://orcid.org/0000-0001-9485-4776) ${ }^{1}$

Aline do Monte Gurgel (https://orcid.org/0000-0002-5981-3597) ${ }^{2}$

Idê Gomes Dantas Gurgel (https://orcid.org/0000-0002-2958-683X) ${ }^{2}$

${ }^{1}$ Secretaria Estadual de

Saúde de Pernambuco.

R. Dona Maria Augusta

Nogueira 519, Bongi. 50751-

530 Recife PE Brasil.

prilunab@gmail.com

${ }^{2}$ Instituto Aggeu Magalhães,

Fundação Oswaldo Cruz.

Recife PE Brasil.

\begin{abstract}
Malathion has been widely used worldwide in arbovirus control programs. In 2015, it was classified by the International Agency for Research on Cancer (IARC) as a probable carcinogen to humans. This work aimed to systematize the evidence of the carcinogenic and mutagenic effects associated with the exposure of malathion and its analogs, malaoxon and isomalathion. The search was carried out in Toxline, PubMed and Scopus databases for original papers published from 1983 to 2015. In all, 73 papers were selected from a total of 273 eligible papers. The results of in vitro and in vivo studies showed mainly genetic and chromosomal damages caused by malathion. The epidemiological studies evidenced significant positive associations for thyroid, breast, and ovarian cancers in menopausal women. This evidence of the carcinogenic effect of malathion should be considered before its use in arbovirus control programs.
\end{abstract}

Key words Malathion, Carcinogenicity Tests, Mutagenicity Tests, Environmental Health
Resumo O agrotóxico malathion vem sendo amplamente utilizado no mundo em programas de controle de arboviroses e em 2015 foi classificado pela Agência Internacional para Pesquisas em Câncer (IARC) como provável agente carcinogênico para seres humanos. Este trabalho objetivou a sistematização das evidências dos efeitos carcinogênicos e mutagênicos associados à exposição do malathion e seus análogos, malaoxon e isomalathion. A busca foi realizada nas bases de dados TOXLINE, PUBMED e SCOPUS por artigos originais publicados de 1983 a 2015. Do total de 273 artigos elegíveis, foram selecionados 73 . Os resultados dos estudos in vitro e in vivo evidenciaram danos genéticos e cromossômicos provocados pelo malathion; os estudos epidemiológicos evidenciaram associações significativamente positivas para cânceres de tireóide, de mama, e ovariano em mulheres na menopausa. Estas evidências do efeito carcinogênico do malathion devem ser considerados diante de sua utilização em programas de controle de arboviroses.

Palavras-chave Malation, Testes de Carcinogenicidade, Testes de Mutagenicidade, Saúde Ambiental 


\section{Introdução}

Os agrotóxicos são compostos químicos utilizados extensivamente na agricultura, para o controle químico de espécies espontâneas em ambiente urbano e de vetores, em campanhas de saúde pública ${ }^{1}$ e representam perigo para os seres humanos e para a natureza ${ }^{2}$. Dentre os mais utilizados, destacam-se o grupo dos organofosforados (OP) que são inibidores irreversíveis da acetilcolinesterase $(\mathrm{AChE})^{3}$. O consequente acúmulo desta molécula no organismo provoca efeitos tóxicos sobre diferentes órgãos e sistemas, como alterações no sistema nervoso, imunológicas, endócrinas e outras ${ }^{4-7}$. Dentre seus possíveis efeitos crônicos, caracterizados por surgimento tardio, estão danos potencialmente irreversíveis, como paralisias e neoplasias ${ }^{8}$.

No Brasil, com o crescimento exponencial da epidemia de dengue, em 2015, em que se registrou mais de 1 milhão de casos confirmados ${ }^{9} \mathrm{e}$ com o surgimento da febre Chikungunya (2014) e da epidemia do Zika vírus (2015), com consequências ainda mais nocivas à população, foi demandada a revisão do Programa Nacional de Controle do Aedes aegypti (mosquito transmissor), com intensificação do uso de inseticidas para este mosquito, dando seguimento orientações de 2014, com pulverização de Malahion a 30\% diluído em água a Ultra Baixo Volume $(\mathrm{UBV})^{10}$. Este fato foi criticado pela Associação Brasileira de Saúde Coletiva (Abrasco), que divulgou uma nota técnica alertando para os perigos à saúde e ao ambiente ${ }^{11}$.

O malathion (diethyl (dimethoxythiophosphorylthio)succinate) é um OP utilizado em várias culturas para controle de espécies não desejadas e é frequentemente utilizado no controle de insetos ${ }^{12}$, cujas formulações comercializadas pode conter até doze impurezas formadas durante a fabricação e armazenamento ${ }^{13}$. Entre as impurezas importantes estão o malaoxon e isomalathion, formados a partir da oxidação ${ }^{14} \mathrm{e}$ da isomerização química ou térmica do malathion, respectivamente ${ }^{15}$.

Sua capacidade mutagênica e potencial efeito carcinogênico vem sendo discutidos ${ }^{16-18}$. Entretanto, apesar do uso generalizado, há surpreendentemente poucos estudos sobre a associação entre malathion e câncer, a maioria realizados na América do Norte e Europa, com poucos estudos produzidos em países de economia periférica, onde a exposição é, em geral, muito maior ${ }^{19}$. Alguns autores apontam seus achados como algo preocupante, uma vez que o malathion tem apre- sentado elevados índices de atividade carcinogênica, além de propriedades químicas que o aproxima de outras substâncias reconhecidamente carcinogênicas como aflatoxina e benzopireno ${ }^{20}$.

Na década de 1980, o malathion foi avaliado pela Agência Internacional de Pesquisa em Câncer (IARC) como não classificável quanto à sua carcinogenicidade para seres humanos (Grupo $3)^{21,22}$, pela falta de evidências suficientes para a carcinogenicidade do malathion ou seu metabólito malaoxon em animais experimentais, e pela indisponibilidade de dados para seres humanos naquele período. Em 2015 a IARC publicou um novo documento, classificando o agrotóxico como provável agente carcinogênico para os seres humanos (Grupo 2A) ${ }^{19}$.

Tendo em vista a ampla utilização do malathion como agrotóxico em todo o mundo, tanto na agricultura como na saúde pública e diante dos riscos que ele pode trazer, este trabalho teve como objetivo a sistematização das evidências dos efeitos carcinogênicos e mutagênicos associados à exposição a este agrotóxico e seus análogos malaoxon e isomalathion.

\section{Métodos}

\section{Dados da Busca}

Foi realizada uma revisão sistemática da literatura, por meio da busca de artigos científicos publicados entre 1983 a 2015. Foi escolhido 1983 como ponto inicial da pesquisa, devido à monografia da IARC ${ }^{21}$, publicada naquele ano, considerar o malathion como "não classificável quanto à sua carcinogenicidade para seres humanos (Grupo 3)", concluindo que não havia evidências suficientes para a carcinogenicidade do malathion ou do seu metabólito malaoxon em experimentos com animais, e pela ausência de dados relacionados a seres humanos.

A busca foi realizada nas bases de dados eletrônicas SCOPUS, PUBMED e TOXLINE (nesta última foram excluídos os resultados da PUBMED), sendo empregados dois grupos comando. O primeiro, composto por termos relativos à exposição de interesse (malathion, malaoxon e isomalathion), e o segundo contendo termos relativos ao desfecho de interesse (cancer, "carcinogenicity tests", carcinogens, neoplasms, mutagenesis, "mutagenicity tests" e mutagens). Para a seleção dos descritores/termos utilizados, foi realizada consulta no Medical Subject Headings (MeSH). Para combinação dos termos em cada 
grupo, foi utilizado o operador booleano "OR" e para a combinação entre os grupos foi utilizado o operador "AND".

\section{Seleção dos artigos}

Foram selecionados estudos originais que apresentassem resultados sobre o efeito carcinogênico e/ou mutagênico do malathion, malaoxon e isomalathion em seres vivos. Os artigos de revisão, dissertações e teses identificados nas buscas foram excluídos. Foram considerados manuscritos publicados na língua Inglesa, Portuguesa e Espanhola.

Os artigos foram selecionados pelas pesquisadoras (autoras deste artigo) em duas etapas. $\mathrm{Na}$ primeira, duas pesquisadoras realizaram, separadamente, a leitura do título e resumo dos artigos para seleção dos que deveriam compor a base da pesquisa. Aqueles que se apresentaram sem resumo ou sem informações suficientes para a tomada de decisão foram mantidos para a etapa seguinte. Os casos de discordância foram resolvidos por uma terceira pesquisadora.

$\mathrm{Na}$ segunda etapa, todos os artigos selecionados que atenderam aos critérios de inclusão/exclusão e aqueles com informações insuficientes para a tomada de decisão foram analisados na íntegra. Os dados de ambos os revisores foram novamente confrontados e as divergências foram solucionadas pelo terceiro revisor.

Os manuscritos selecionados foram analisados para a extração dos seguintes dados: autores, ano de publicação, periódico, delineamento do estudo, população alvo, país da população em estudo (nos estudos epidemiológicos), exposição (malathion, malaoxon, isomalathion, exposição mista) e principais resultados identificados quanto ao efeito carcinogênico e mutagênico do malathion, do malaoxon e do isomalathion.

As buscas foram realizadas entre 04 e 12 de julho de 2016. Foram utilizados filtros para seleção dos idiomas e período de publicação dos manuscritos nas três bases de dados.

\section{Resultados e Discussão}

Foram encontrados 178 resultados no Scopus, 147 no Pubmed e 92 no Toxline, totalizando 417 artigos (Figura 1). Foram identificadas 142 repetições, além de dois artigos publicados em outros idiomas (alemão e chinês), permanecendo 273 para avaliação da elegibilidade.

Após aplicação dos critérios de inclusão e exclusão, e da avaliação nas duas etapas, foram in- cluídos 73 artigos neste trabalho, todos na língua inglesa. Destes, 24 correspondem a estudos experimentais in vitro, incluindo testes de mutagenicidade e culturas celulares tanto de animais como de seres humanos; 24 estudos experimentais in vivo, incluindo camundongos, ratos, hamster, aves, sapos e moscas; 25 estudos epidemiológicos, incluindo coortes, caso-controles e estudos transversais (dois deles com experimentos in $v i$ tro associados). Os resultados encontrados quanto aos trabalhos experimentais in vitro que avaliaram o efeito carcinogênico e/ou mutagênico do malathion e seus análogos estão sintetizados no Quadro 1.

Três estudos obtiveram aumentos significativos dos danos ao DNA de linfócitos do sangue periférico de ratos após exposição ao malathion $^{1,18,26}$. Um aumento das frequências de alterações cromossômicas em células da medula óssea de ratos de maneira dose-dependente ao malathion também foi observado ${ }^{26}$. Ojha e Gupta $^{18}$, além de observarem a redução significativa da viabilidade celular e o aumento significativo de quebras tanto em fita simples como em fita dupla do DNA, verificaram a formação de DPC, em tempo e dose dependentes após a exposição dos linfócitos de ratos ao malathion tanto individualmente como em mistura a outros dois organofosforados (clorpirifós e parationa-metílica), quando comparado ao controle. Uma vez que os DPC correspondem a lesões tóxicas associadas a mecanismos de toxicidade de compostos carcinogênicos ${ }^{45}$, o estudo evidencia o efeito carcinogênico do malathion. A pesquisa ainda conclui que o malathion, juntamente com os demais agrotóxicos do estudo, deve gerar lesões oxidativas dos pares de bases do DNA, possuindo potencial genotóxico para alterar a expressão enzimas.

Em culturas de linfócitos do sangue periférico humano expostas ao malathion, resultados mostraram aumento dose-dependente de alterações cromossômicas e trocas de cromátides-irmãs ${ }^{37,39}$, além do efeito alquilante de nucleotídeos específicos do $\mathrm{DNA}^{34}$. Ao comparar o malathion aos seus dois análogos, não foram observadas alterações significativas de danos ao DNA dessas mesmas células $^{32}$, diferentemente do malaoxon e isomalathion, que promoveram lesões no DNA de maneira dose-dependente. $\mathrm{O}$ estudo de Blasiak et al. ${ }^{32}$ foi o único a avaliar os três agentes químicos na mesma pesquisa, e concluiu que os danos provocados ao DNA pelo malaoxon são mais acentuados que os provocados pelo isomalathion.

Josse et al. $^{23}$ avaliaram os efeitos do malathion e do isomalathion individualmente e combinados 


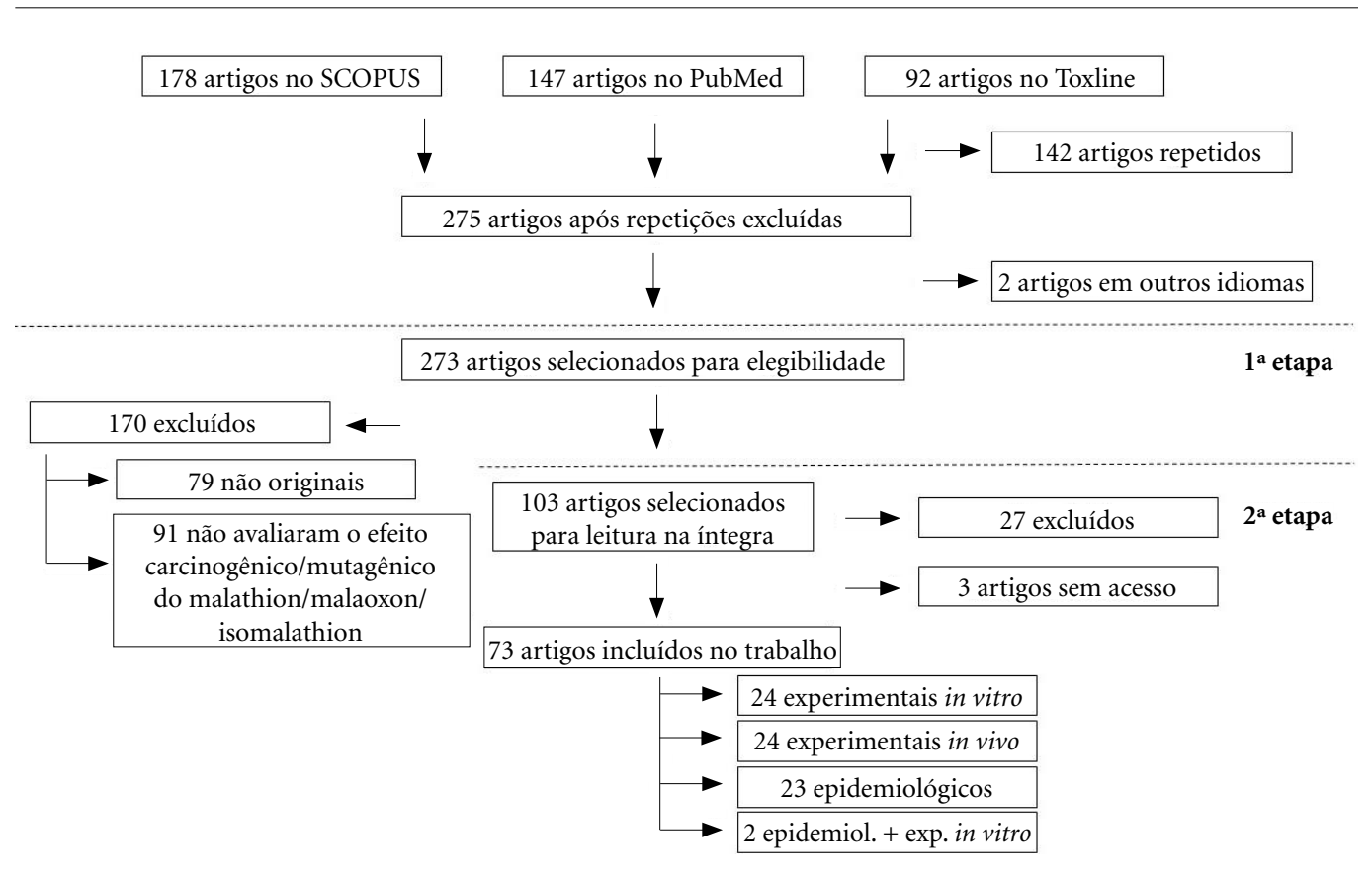

Figura 1. Fluxograma ilustrando os artigos que foram incluídos e excluídos na revisão sistemática, com razões para exclusão.

Fonte: Elaborada pelas autoras.

sobre linhagem de células HepaRG de fígado humano e evidenciaram que, apesar do isomalathion ter sido muito mais citotóxico que o malathion, ambas as substâncias apresentaram efeitos mutagênicos semelhantes nesses hepatócitos. Já Błasiak e Trzeciak ${ }^{33}$ afirmam que os danos ao DNA de linfócitos humanos são causados pelo isomalathion e não pelo seu composto original.

Em relação à exposição do malaoxon, observou-se contradição entre os resultados encontrados. Blasiak e Kowalik ${ }^{31}$ constataram que o malaoxon promoveu um aumento significativo da extensão de danos ao DNA em linfócitos do sangue periférico humano no Ensaio Cometa, sendo maior com o aumento da dose. No ensaio de células de cariocarcinoma de linhagem humana (JAR) (modelo aceitável para células placentárias humanas), o mesmo agente não foi apontado como responsável pelos efeitos cito e genotóxicos nestas células in vitro, mas sim o malathion. Autores defendem que metabólitos de agrotóxicos com resultados contraditórios quanto ao seu potencial carcinogênico devem ser estudados, uma vez que os mesmos podem representar os verdadeiros carcinógenos ${ }^{46}$.
O malathion também foi avaliado em testes de mutação gênica que empregam bactérias, como o teste de lactam de Salmonella (método de detecção de genotoxinas) ${ }^{35}$, fago-MicroScreen (sistema miniaturizado que utiliza a indução de prófago em Escherichia coli X como um indicador de dano genético ${ }^{41}$ e teste de Ames Salmonella ${ }^{40}$. Nos três estudos encontrados, os resultados foram negativos quanto à atividade mutagênica do malathion, não sendo observadas no último teste atividades com ou sem ativação com fração $S 9$ de fígado de rato nas respectivas doses não tóxicas $(33 \mathrm{mg} / \mathrm{L})$ e $90 \%$ tóxicas $(1650 \mathrm{mg} / \mathrm{L})$. Flessel et al. ${ }^{47}$, em revisão de literatura, também observaram os mesmos resultados e concluíram que o malathion não parece induzir mutações pontuais no DNA em sistemas bacterianos.

Dos 24 estudos experimentais in vivo encontrados nesta revisão sistemática, vinte realizaram os experimentos em ratos, camundongos ou hamsters, os demais avaliaram os efeitos do agrotóxico em aves, sapo e moscas. No Quadro 2 estão os principais resultados desses trabalhos.

Degraeve et al. ${ }^{70}$, em 1984, relataram que o Dynafos e o Phosan Plus, inseticidas que possuem 


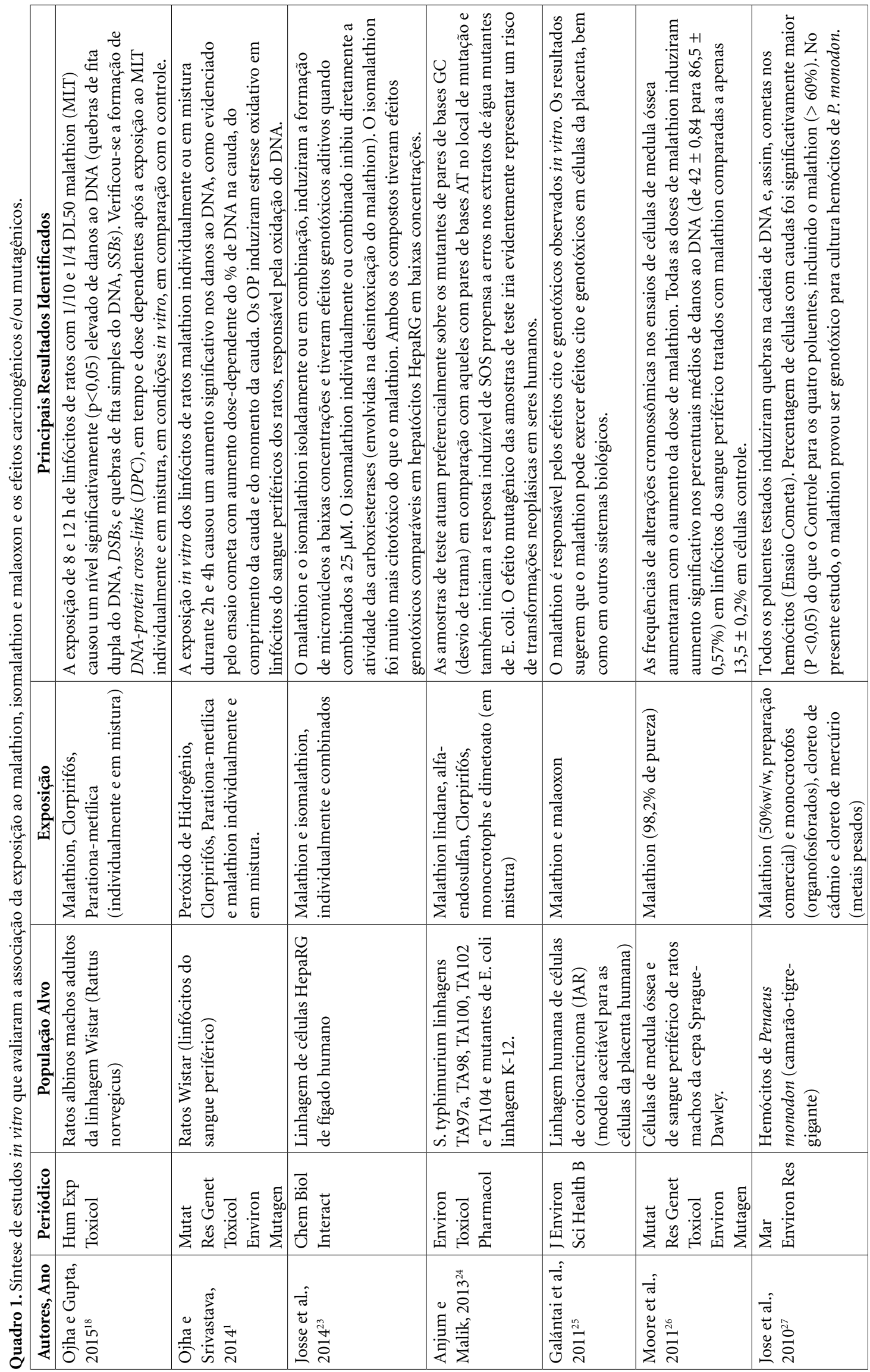




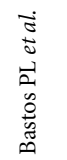

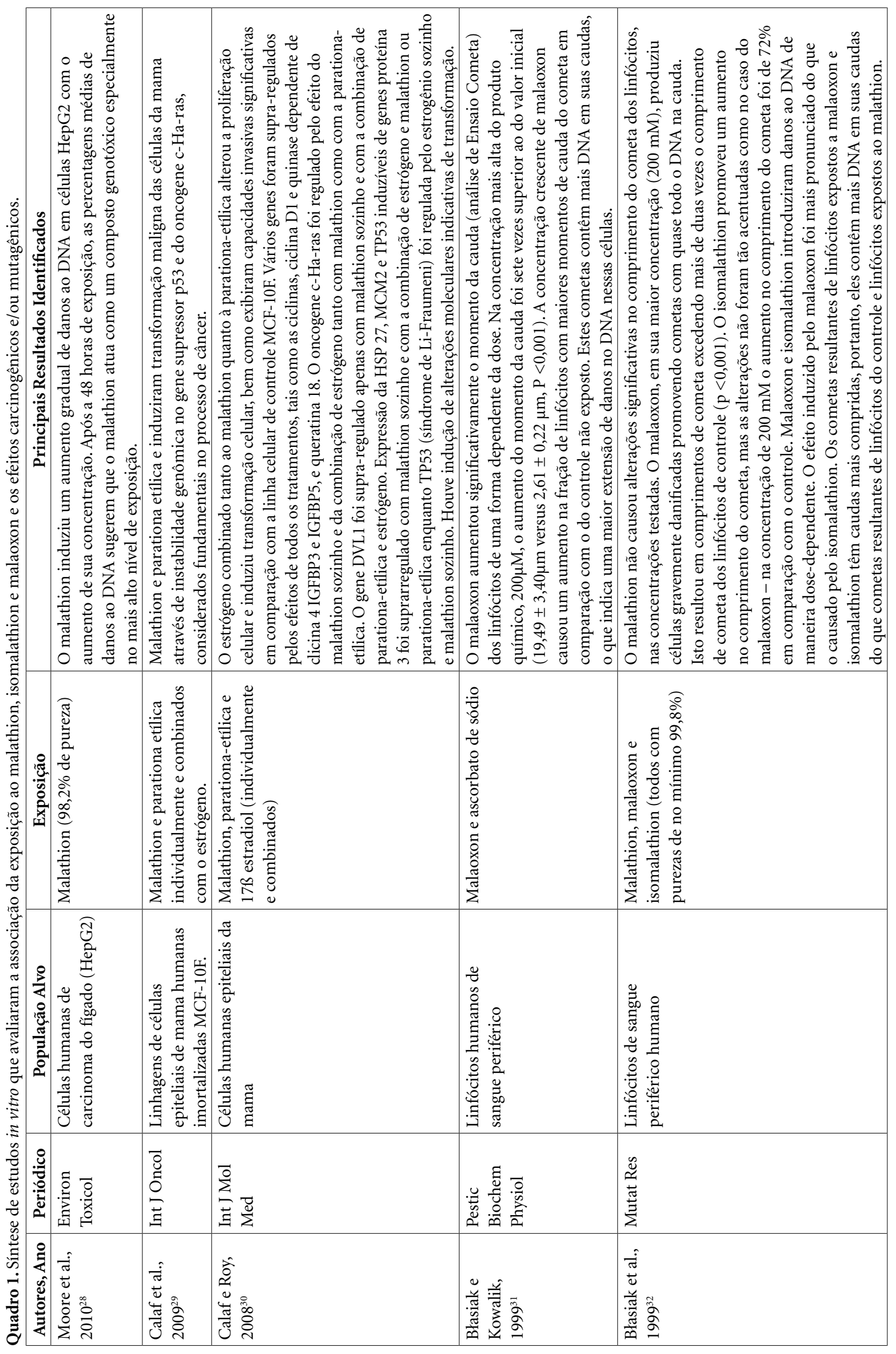




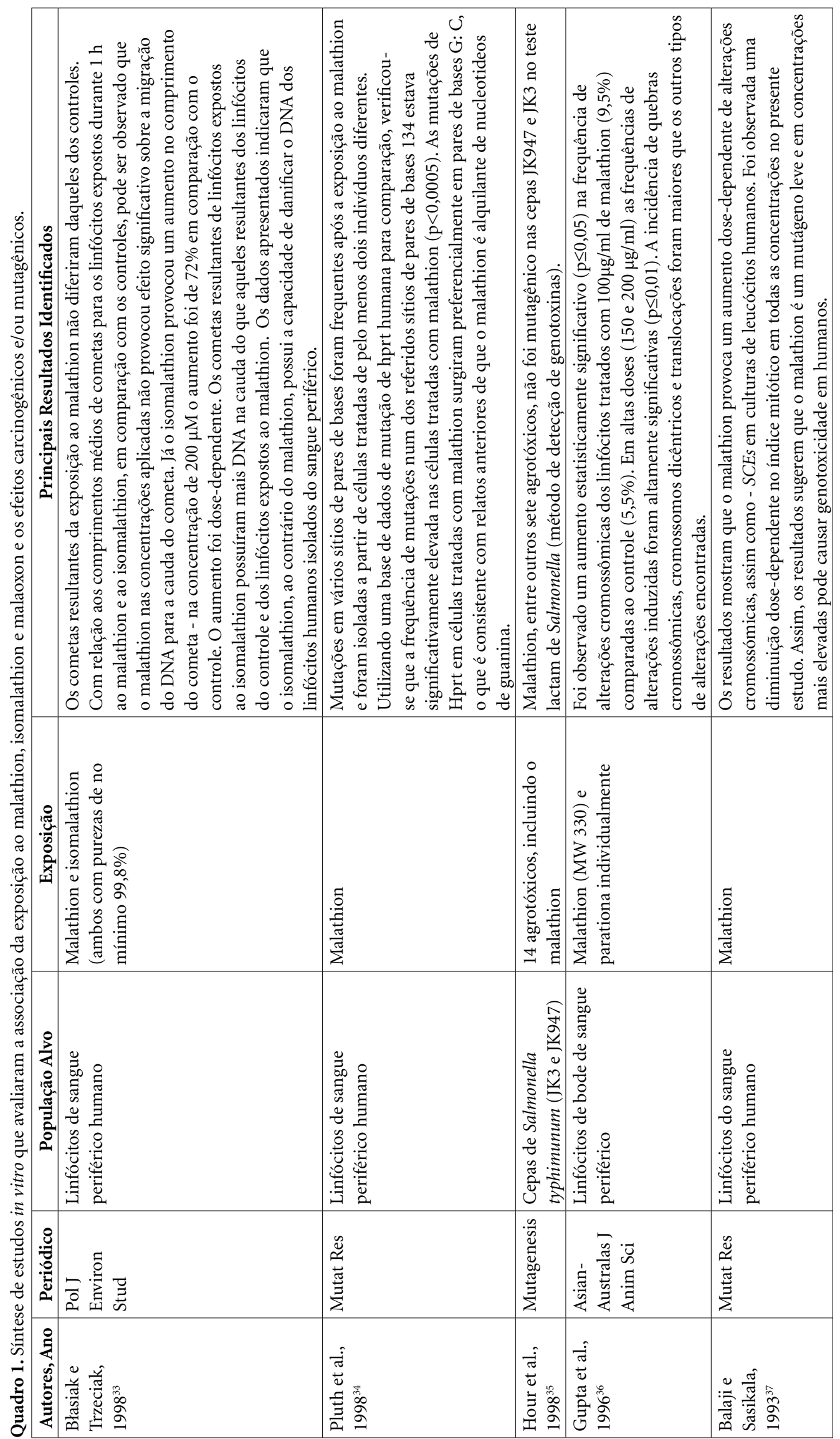


$\dot{5}$
5
0
0
0
0
0
0
0

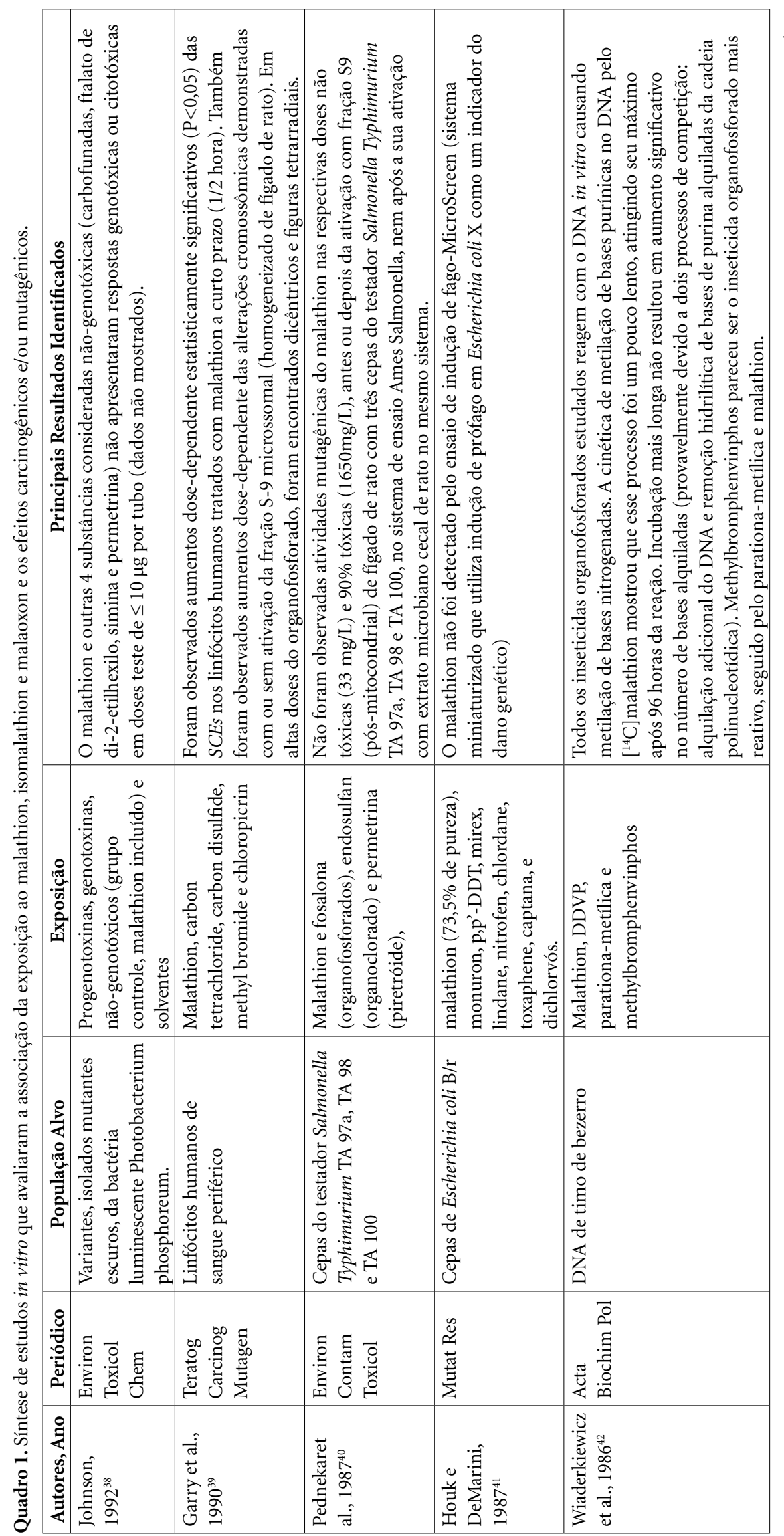




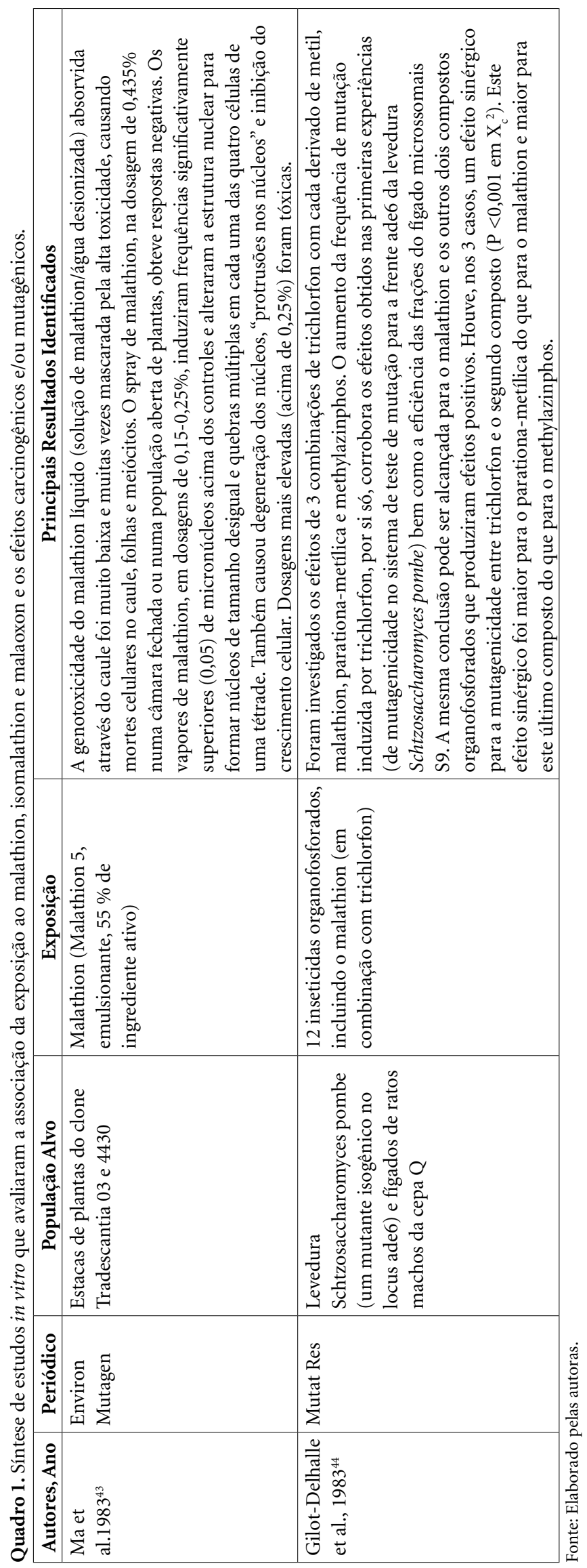




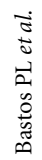

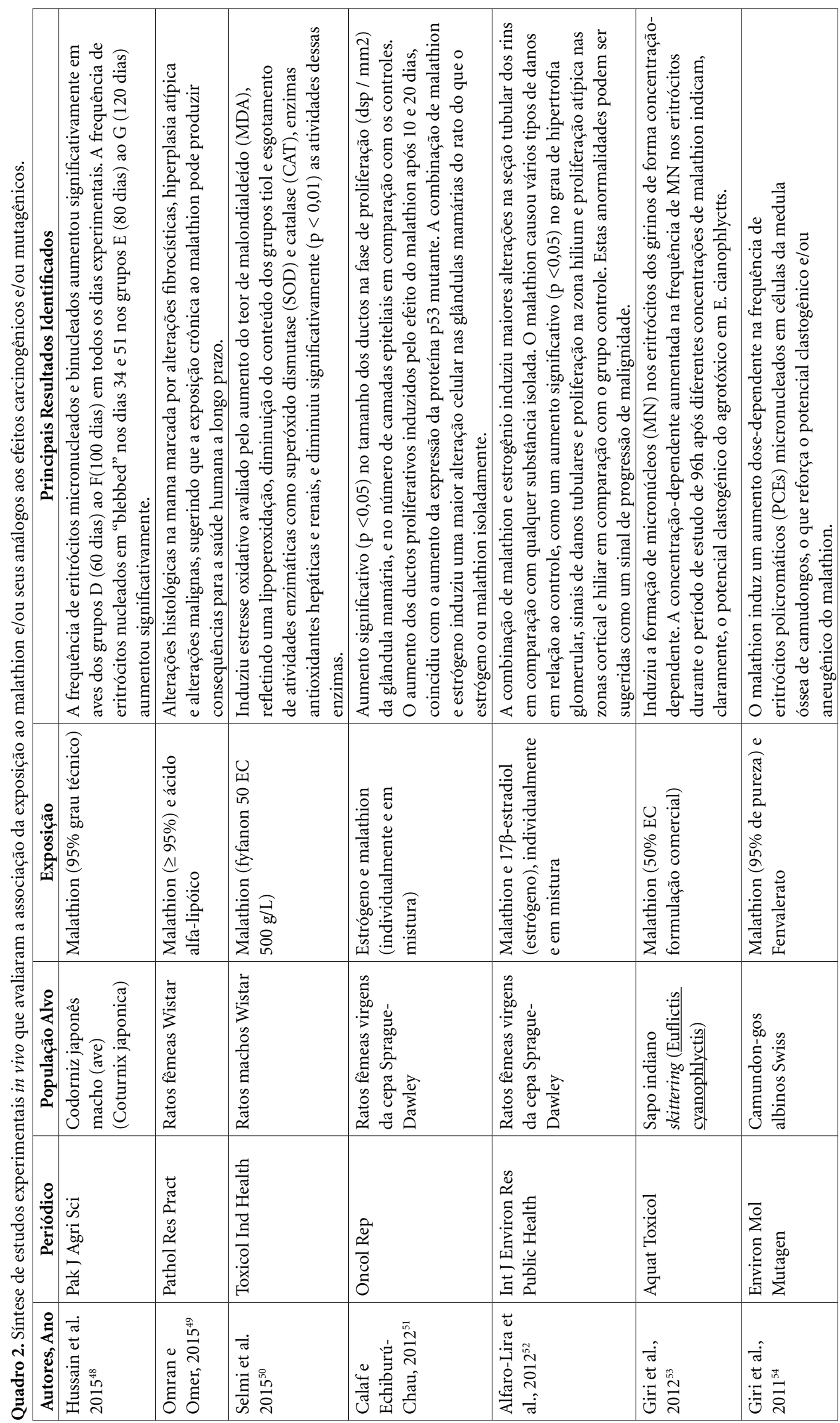




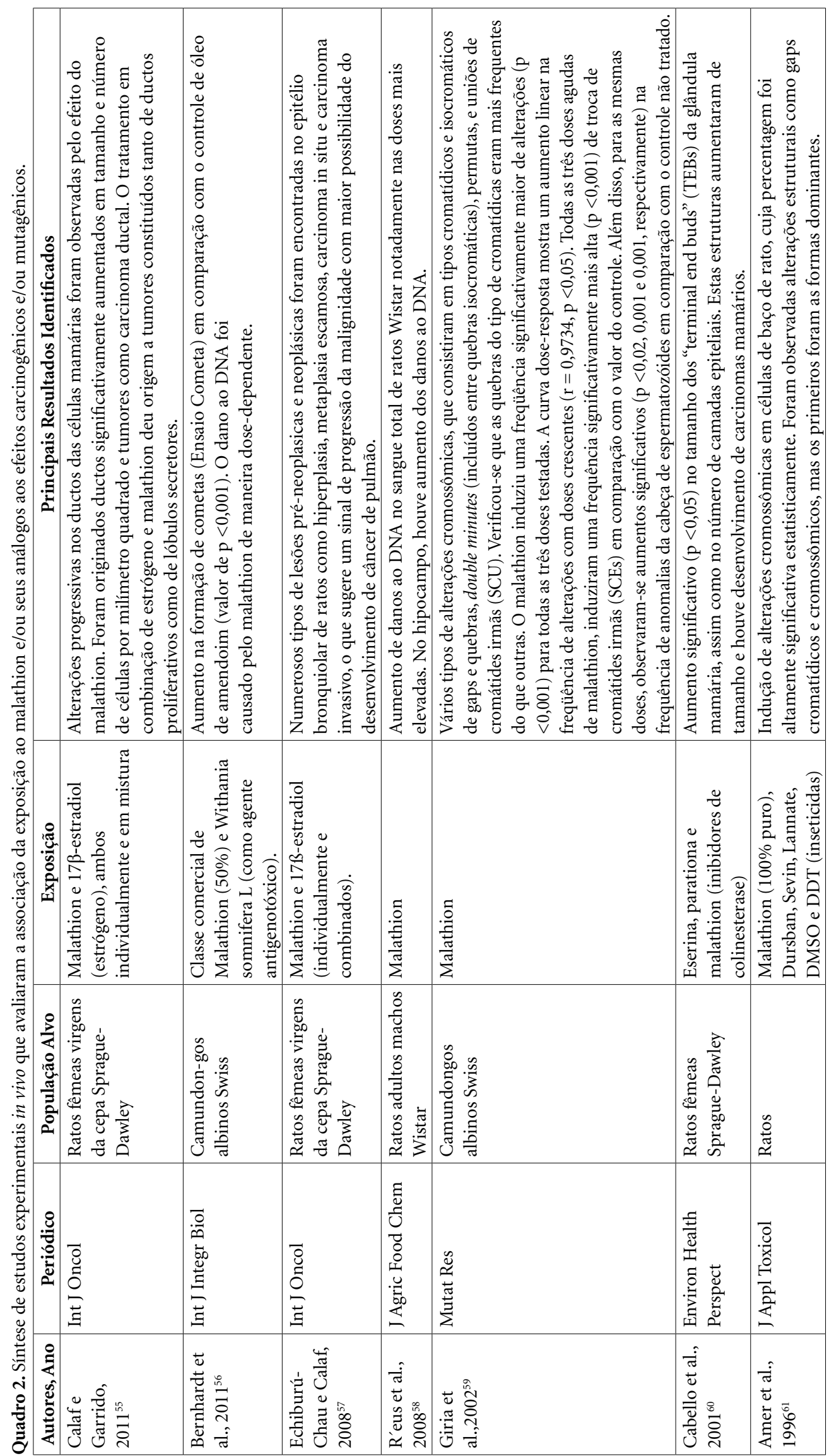


$\overrightarrow{5}$
\pm
0
0
0
0
0
0
0

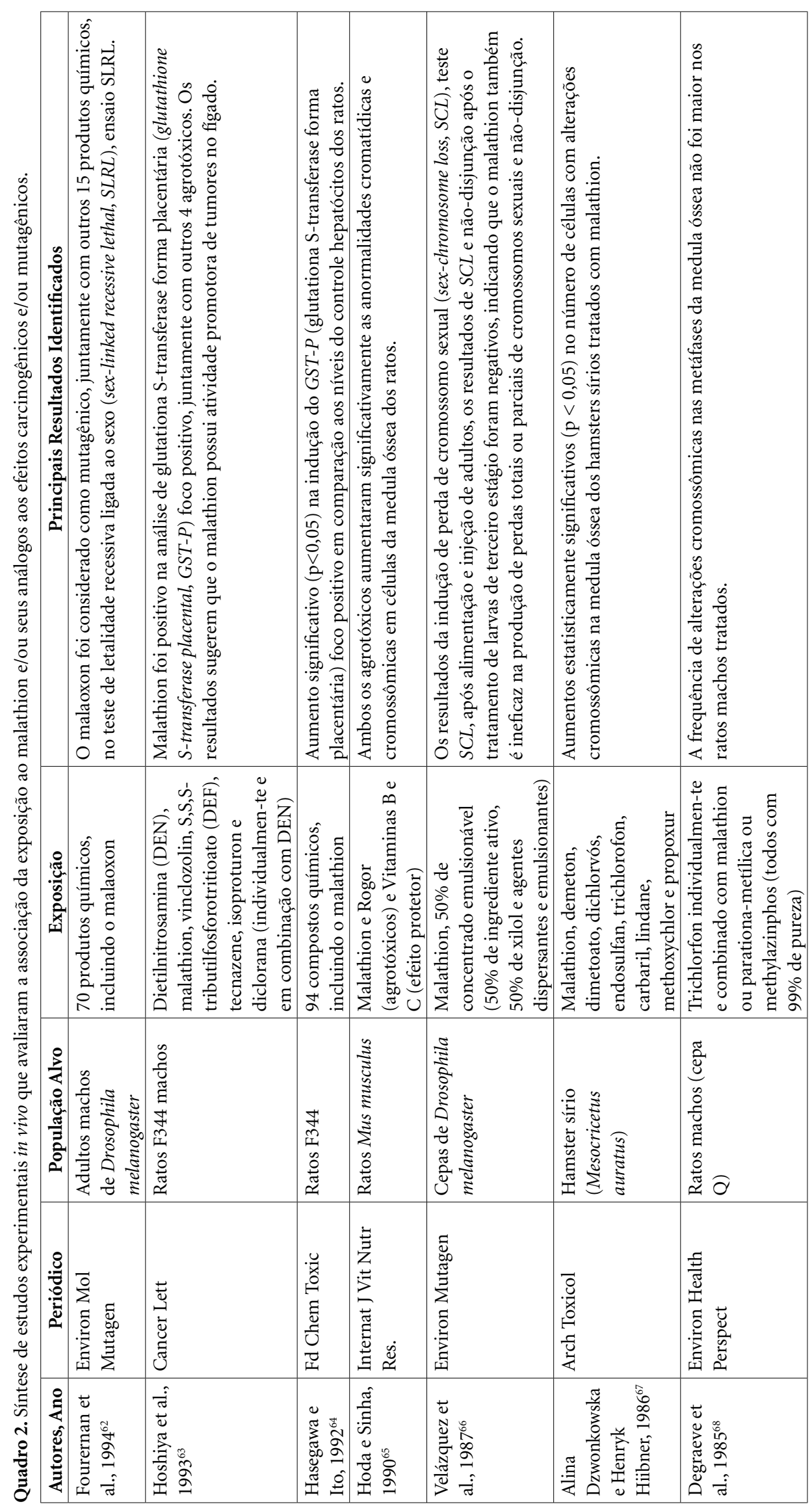




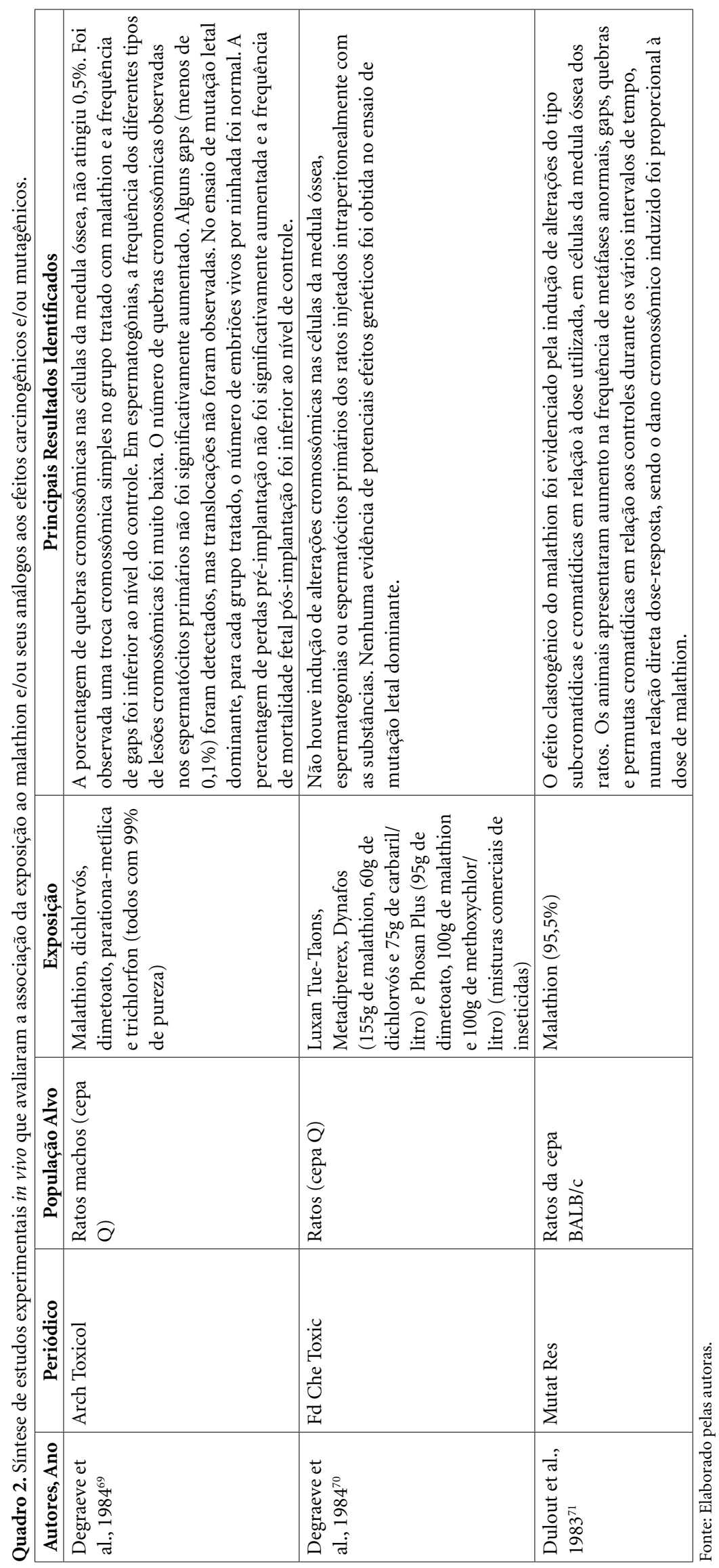


o malathion em sua composição, não induziram alterações cromossômicas em células da medula óssea, espermatogônias ou espermatócitos primários, nem alterações no ensaio de mutação letal dominante, após injeção intraperitoneal de ratos da cepa Q. O estudo não possui qualquer dado com relação a impurezas, solventes, emulsionates etc. nesses compostos, limitando seus resultados.

No mesmo ano, esses autores expuseram ratos da mesma cepa ao malathion com $99 \%$ de pureza, mediante a ingestão de água contendo pequenas quantidades do organofosforado (8 $\mathrm{ppm}$, correspondendo ao maior valor permitido na Bélgica para resíduos do agrotóxico em frutas e vegetais) em 5 dias por semana durante 7 semanas consecutivas ${ }^{69}$. Mais uma vez, não se observou aumento significativo de quebras ou gaps cromossômicas nos mesmos tipos celulares do trabalho anterior, nem no ensaio de mutação letal dominante, porém há poucas informações acerca da técnica de análise utilizada para pesquisa dessas alterações. Em 1985, o grupo avaliou os efeitos sobre ratos injetados com o malathion (com doses de $150 \mathrm{mg} / \mathrm{kg}$ ) combinado ao trichlorfon ( $50 \mathrm{mg} / \mathrm{kg}$ ) e, também, não evidenciou efeitos citogenéticos (quebras, gaps e trocas cromatídicas) da combinação ${ }^{68}$.

Do total de estudos experimentais in vivo encontrados neste trabalho, apenas quatro não evidenciaram associação positiva entre os efeitos mutagênicos e o malathion, todos da década de 1980. Os três primeiros foram os citados acima, o quarto e último deles data de 1987, que obteve resultados negativos em relação à produção de perdas de cromossomos sexuais e não-disjunção em cepas de Drosophila melanogaster expostas a malthion com $50 \%$ do ingrediente ativo, percentual este que pode ter influenciado de maneira importante os resultados encontrados ${ }^{66}$. Desde então, houve mais 17 estudos com resultados positivos para carcinogenicidade e genotoxicidade do malathion, e um para genotoxicidade do malaoxon.

Honda e Sinha ${ }^{65}$, evidenciaram um aumento significativo (a um nível de $0,1 \%$ ) das alterações cromatídicas das células da medula óssea, após a exposição de ratos Mus musculus. Camudongos albinos Swiss expostos ao malathion apresentaram metáfases de células da medula óssea com vários tipos de alterações cromossômicas, tendo o agrotóxico induzido frequência significativamente maior $(\mathrm{p}<0,001)$ de alterações nas três doses agudas testadas $(2,5,5$ e $10 \mathrm{mg} / \mathrm{kg})$ que no controle, além de frequências aumentadas de tro- cas de cromátides-irmãs e anomalias da cabeça de espermatozoides ${ }^{59}$. Giri et al. ${ }^{54}$ relataram o aumento dose-dependente na frequência de eritrócitos policromáticos micronucleados em células da medula óssea de camundongos da mesma espécie, após exposição in vivo a malathion com 95\% de pureza.

Em relação à carcinogenicidade do malathion em experimentos in vivo, o primeiro manuscrito encontrado é de 1992, no qual o agrotóxico promoveu um aumento significativo $(p<0,05)$ na indução de foco GST-P positivo em hepatócitos de ratos F344 em comparação com o controle ${ }^{64}$. A expressão da enzima GST-P é normalmente baixa nos hepatócitos fetais, adultos quiescentes ou em regeneração, placenta, coração e em outros órgãos de ratos machos, contudo nódulos hiperplásicos e tumores hepáticos induzidos quimicamente apresentam valores de GST-P cerca de 20 a 50 vezes e de 10 a 30 vezes, respectivamente, quando comparados aos valores do fígado normal de rato $^{72}$. Assim, o estudo sugere a possibilidade do malathion ser um hepatocarcinógeno ou hepatopromotor fraco. Já o estudo de Hoshiya et al. ${ }^{63}$, também com ratos F344, conclui que o malathion possui atividade promotora de tumores no fígado.

Em ratos fêmeas virgens da cepa SpragueDawley, estudos têm investigado os efeitos carcinogênicos do malathion e do estrógeno, individualmente e combinados. Calaf e Garrido ${ }^{55}$ observaram alterações progressivas nos ductos das células mamárias dos ratos tratados com malathion isolado em comparação com o controle após 240 dias do tratamento. Calaf e $\mathrm{Chau}^{51}$, além do aumento significativo $(p<0,05)$ no tamanho dos ductos na fase de proliferação da glândula mamária de ratos tratados com o agrotóxico, encontraram um aumento da expressão da proteína p53 mutante, marcadora de detecção tumoral. Numerosos tipos de alterações pré-neoplásicas no epitélio bronquiolar de ratos injetados com malathion também foram encontradas, além de carcinomas in $s i t u^{57}$. Em tecido renal de ratos expostos ao malathion, resultados sugerem anormalidades com sinais de malignidade ${ }^{52}$.

$\mathrm{Na}$ maioria dos estudos anteriormente ci$\operatorname{tados}^{51,52,57}$, o tratamento com a combinação de malathion e estrógeno induziu mais alterações celulares do que os tratamentos com as substâncias isoladamente. Dessa forma, a combinação do agrotóxico, encontrado no ambiente, amplamente utilizado na América Latina e em muitos outros países, e uma substância endógena, como estrogênio, tem capacidade de induzir efeitos 
deletérios nos seres humanos, como o câncer de mama, por exemplo ${ }^{51}$. O estrogênio também pode ser encontrado como poluente em águas superficiais e subterrâneas, e sua presença no ambiente pode ter repercussões toxicológicas e ecotoxicológicas severas, dado que esta substância é reconhecidamente um desregulador endócrino, associado à puberdade precoce, infertilidade $\mathrm{e}$ malformação congênita ${ }^{73-75}$.

Os resultados dos estudos epidemiológicos encontrados nesta revisão sistemática estão sintetizados no Quadro 3. Quanto ao delineamento, foram encontrados onze estudos de caso controle, oito coortes e seis estudos transversais, onde dois destes realizaram, também, experimentos in vitro com linfócitos do sangue periférico humano.

A maioria dos estudos $(\mathrm{n}=16)$ pesquisou as correlações entre a exposição ao malathion e desenvolvimento de cânceres. Dos 25 artigos, 18 foram realizados na América do Norte (12 dos EUA e seis do Canadá), três na Europa, três na Ásia e apenas um na América Latina (Chile). Estes achados corroboram com o manuscrito da IARC, que afirma que pouquíssimos estudos nesse enfoque têm sido realizados em países menos industrializados ${ }^{19}$.

Quanto às evidências de genotoxicidade pesquisadas, Andreotti et al. ${ }^{76}$, em estudo transversal com aplicadores de agrotóxicos do sexo masculino, encontraram associações positivas entre a utilização recente de malathion e o comprimento relativo do telômero mais curto $(\mathrm{p}=0,03)$. $\mathrm{O}$ encurtamento do comprimento do telômero está associado à várias doenças, e a maioria dos estudos têm relatado associações entre ele e aumento do risco de câncer ${ }^{101,102}$.

Em uma coorte prospectiva com pacientes que tentaram suicídio com drogas ou inseticidas, foram observados aumentos temporários, porém significativos, de aneuploidia de leucócitos do sangue periférico $(6,3 \%, \mathrm{p}<0,01)$ e das taxas de alterações cromatídicas $(5,3 \%, \mathrm{p}<0,01)$ e cromossômicas $(1,4 \%, p<0,01)$ após intoxicação com o malathion ${ }^{97}$. Além disso, uma das 14 pessoas intoxicadas pelo organofosforado veio a óbito.

Apenas um dos estudos epidemiológicos que trataram dos efeitos mutagênicos do malathion e de misturas complexas de agrotóxicos que incluíam o organofosforado não observou associação positiva ${ }^{95}$. Este trabalho, realizado tanto com estudo epidemiológico transversal com trabalhadores expostos ao agrotóxico, como com experimentação in vitro de linfócitos do sangue periférico humano também expostos, concluiu que o malathion possui um potencial relativamente baixo para causar dano cromossômico in vitro, sendo as doses correspondentes utilizadas no experimento muito mais elevadas do que aquelas que os aplicadores profissionais estão susceptíveis de serem expostos in vivo, segundo os autores.

Em outro estudo transversal, com um trabalhador ocupacionalmente exposto a agrotóxicos (primeiramente a malathion e fosfina) durante mais de cinco anos, e experimental in vitro com linfócitos do sangue periférico humano expostos ao malathion, foi envidenciado que a mutagenicidade do malathion pode ser detectada a um nível molecular ${ }^{96}$. As alterações moleculares no ensaio hprt foram observadas em doses de malathion que não produziram citotoxicidade in vitro $(\leq 50$ $\mathrm{mg} / \mathrm{ml}$ ) e em níveis de exposição experimentados pelo indivíduo a partir do qual o mutante in vivo foi obtido. Os autores afirmam que alterações semelhantes àquelas refletidas no hprt neste estudo podem ocorrer também em outros loci, especialmente sítios de oncogenes ou genes supressores de tumores, podendo desempenhar um papel na indução de malignidades em indivíduos expostos a este ou a um agente semelhante.

Nos estudos epidemiológicos onde houve a exposição a misturas complexas de agrotóxicos ou combinações que incluíram o malathion, todos os resultados encontraram associações positivas com efeitos genotóxicos ${ }^{77,92,93,99,100}$ e efeito carcinogênico ${ }^{87}$. As investigações de agrotóxicos focadas nos efeitos potenciais dessas substâncias de forma individual têm o propósito de facilitar a análise, além de direcionar políticas públicas. No entanto, exposições múltiplas, apesar de dificultarem a avaliação das relações entre os agrotóxicos e seus efeitos, sejam eles mutagênicos ou cancerígenos, refletem mais exatamente como estes compostos são utilizados na prática ${ }^{87}$.

Dentre os manuscritos que buscaram investigar as correlações entre a exposição do malathion e desenvolvimento de tipos diferentes de cânceres, cinco deles não observaram associações positivas significativas quanto aos casos de Linfoma Não-Hodgkin $(\mathrm{LNH})^{79,91}$, mieloma múltiplo ${ }^{82}$, câncer de próstata ${ }^{85,91}$, sarcoma de tecido mole ${ }^{86}$, cânceres linfático-hematopoiéticos combinados, leucemia, cânceres de pulmão, colon e reto, rim e bexiga e melanoma ${ }^{91}$. Outros três encontraram associações significativamente inversas entre o uso do organofosforado e o surgimento de $\mathrm{LNH}^{78,84}$ e câncer pancreático ${ }^{90}$.

A outra metade deles obteve associações positivas em níveis estatisticamente significativos 


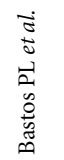

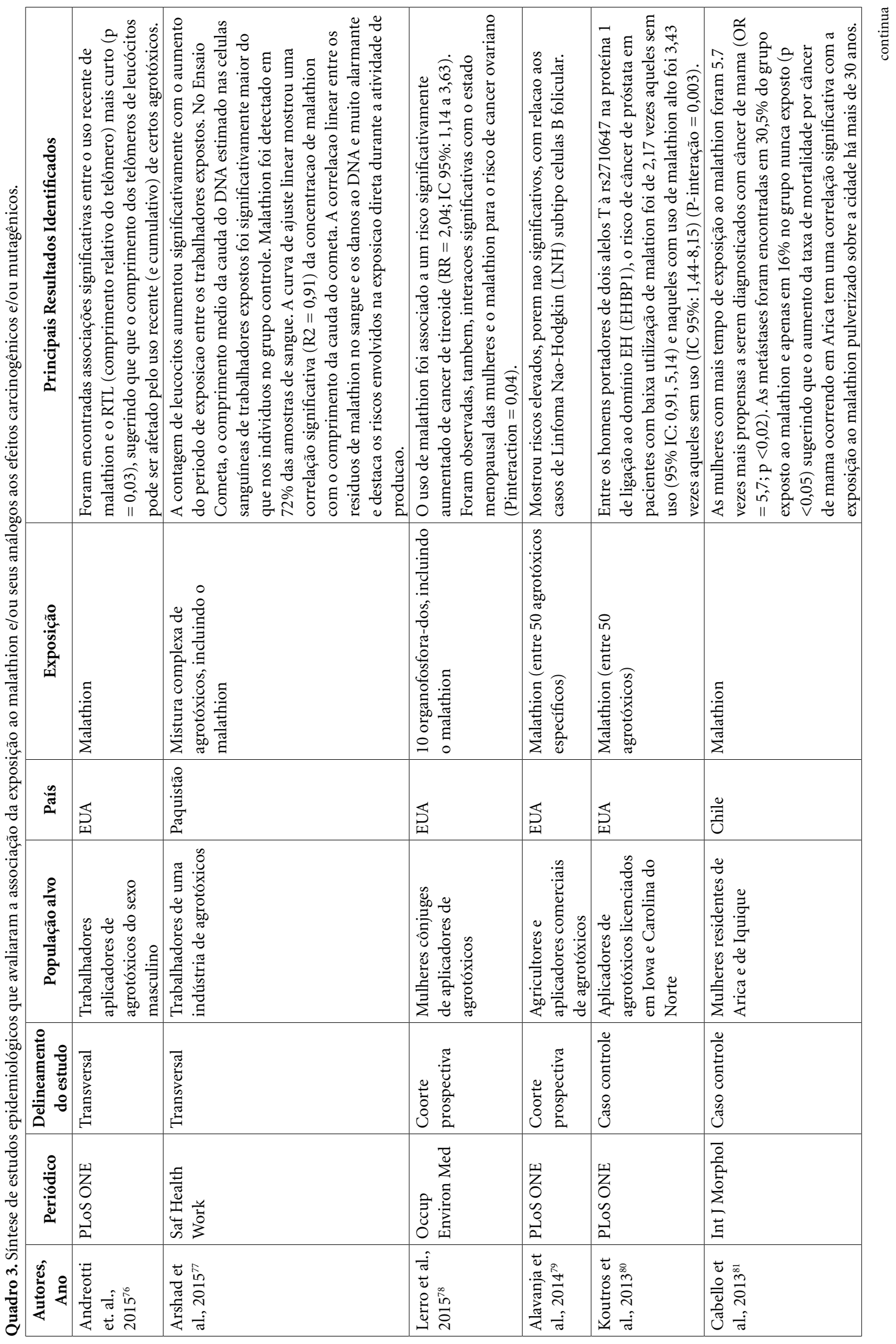




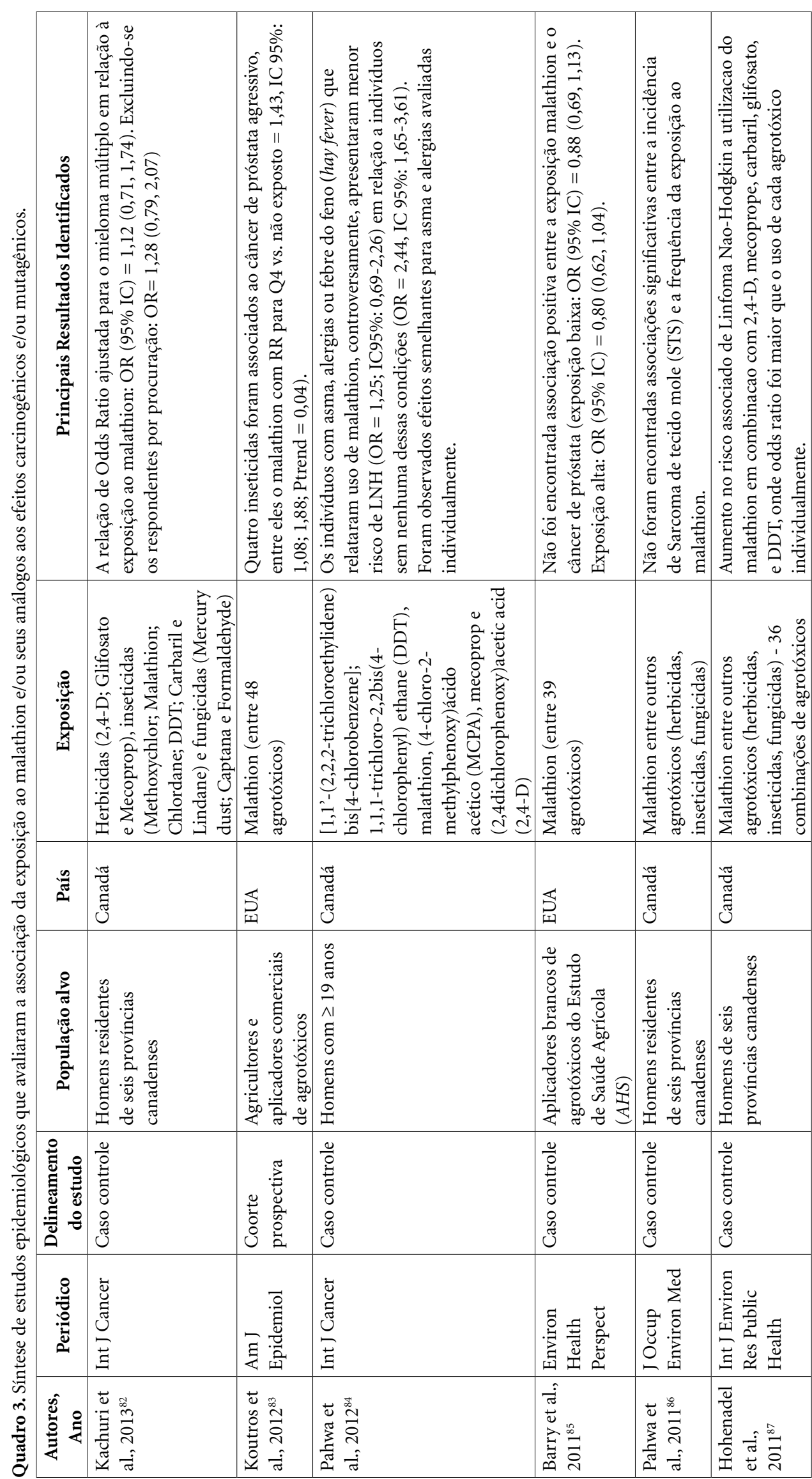


$\overrightarrow{5}$
5
0
0
0
0
0
0
0
0

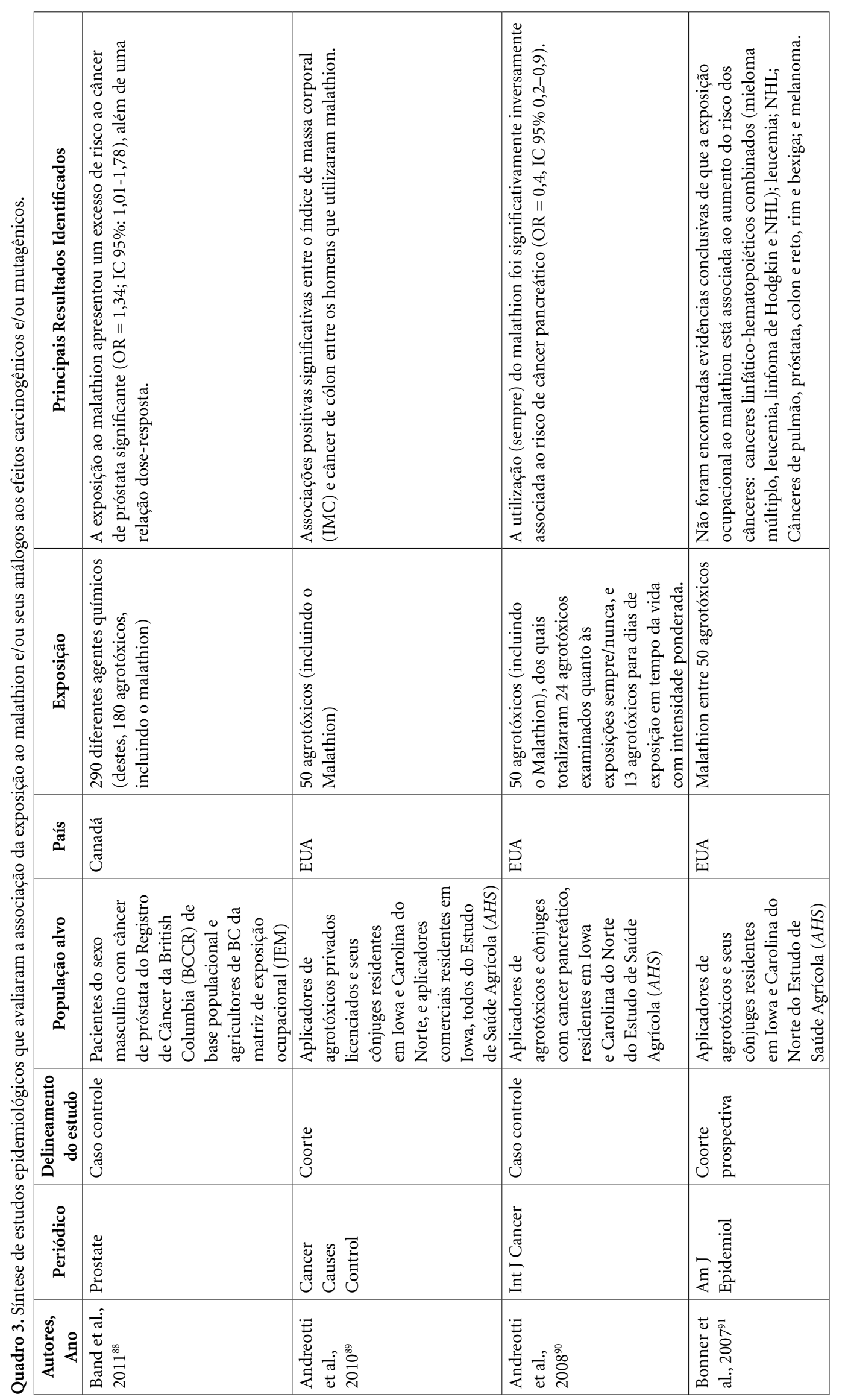




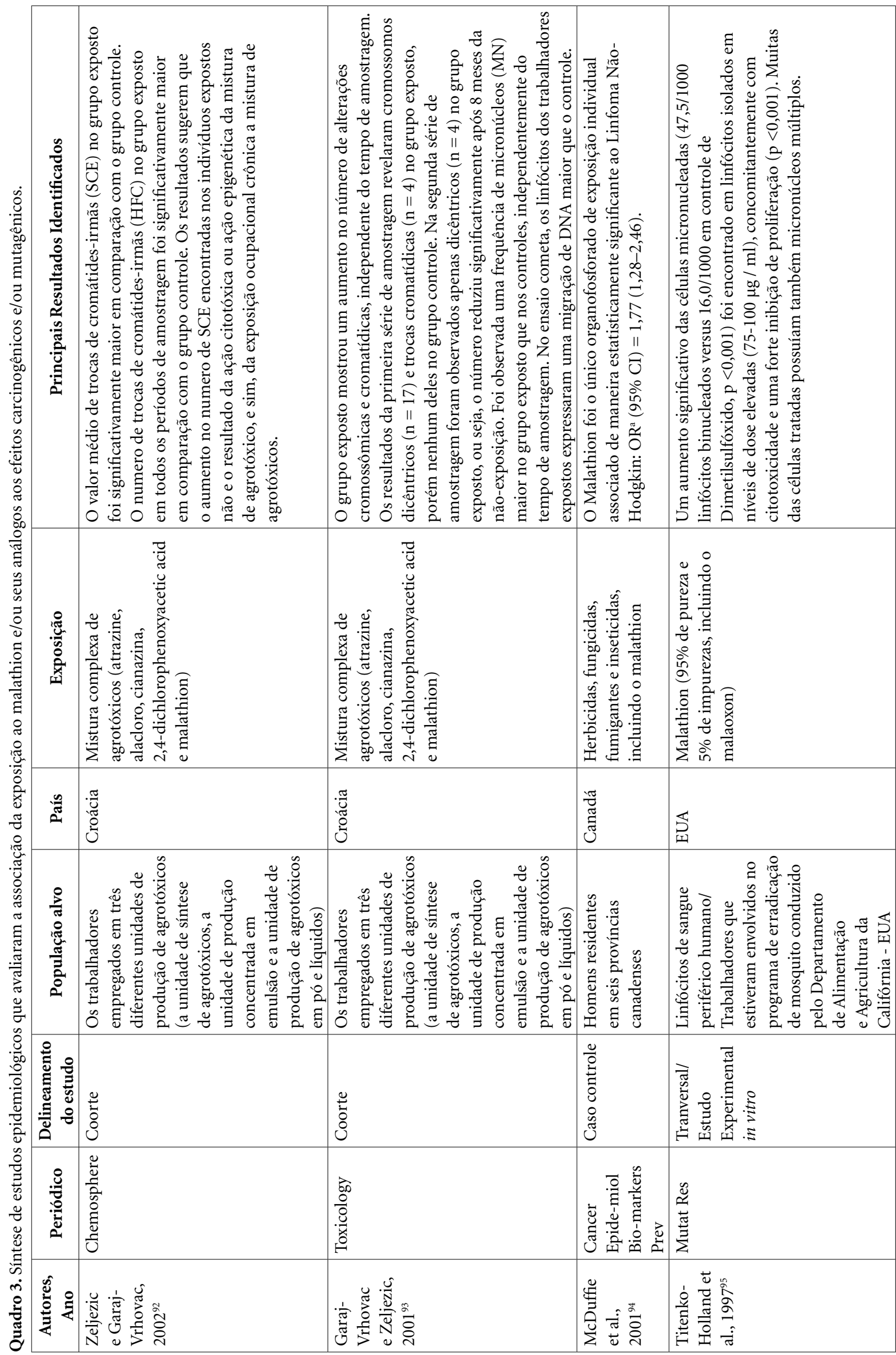




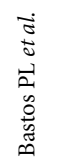

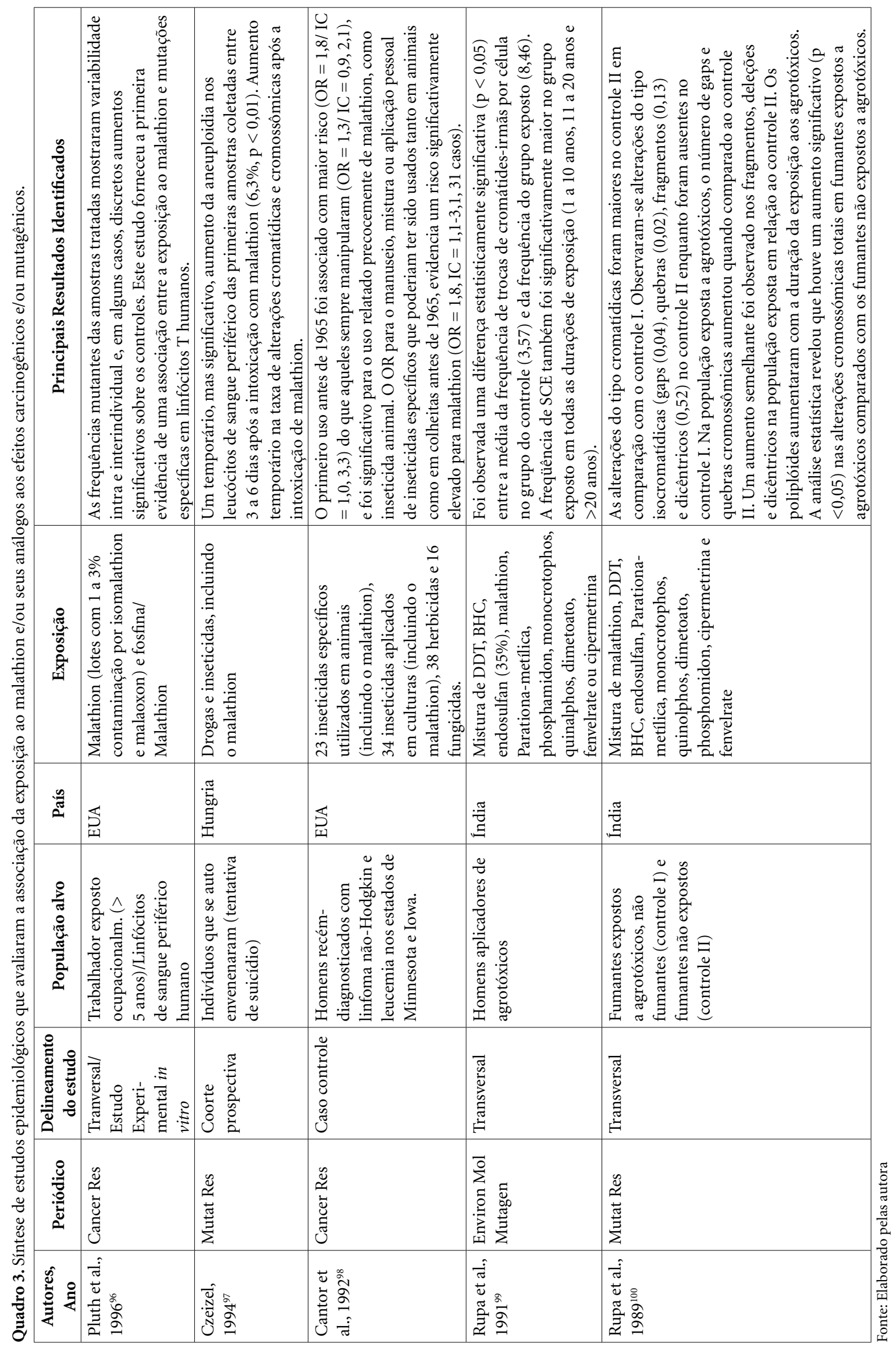


para câncer de tireóide ${ }^{78}$, câncer ovariano em mulheres na menopausa ${ }^{78}$, câncer de prósta$\mathrm{ta}^{80,88}$ e do seu tipo agressivo ${ }^{83}$, câncer de mama ${ }^{81}$, $\mathrm{LNH}^{94,98}$ e entre o índice de massa corporal e câncer de cólon entre homens que utilizaram malathion $^{89}$.

Cerca de 33 anos após a primeira pulverização de malathion sobre a cidade de Arica, no Chile, Cabello et al. ${ }^{81}$ realizaram um estudo de caso-controle com mulheres residentes na cidade e mulheres de Iquique, cidade controle onde nunca houve a pulverização. Os autores observaram que aquelas com mais tempo de exposição ao malathion foram 5,7 vezes mais propensas a serem diagnosticadas com câncer de mama, além de $30,5 \%$ dos casos de metástases encontrados no grupo exposto, contra $16 \%$ no grupo nunca exposto $(\mathrm{p}<0,05)$. O estudo concluiu que o aumento da taxa de mortalidade por câncer de mama ocorrido na cidade de Arica tem uma correlação significativa com a exposição ao malathion pulverizado há mais de três décadas.

De todos os trabalhos incluídos nesta revisão sistemática, apenas um foi realizado no Brasil ${ }^{58}$, o que evidencia a escassez de pesquisas com relação aos efeitos carcinogênicos e genotóxicos do malathion no país. Em contrapartida, a utilização de agrotóxicos, principalmente em países em desenvolvimento, vem apresentando crescimento ao longo dos anos, tornando-se imprescindível a realização de mais estudos acerca da exposição ocupacional e ambiental aos mesmos ${ }^{103}$.

A Abrasco produziu uma Nota Técnica ${ }^{11}$ alertando quanto a produtos como o malathion, utilizados atualmente no controle vetorial em ações de saúde pública, uma vez que os reais danos provocados ao ambiente e à saúde humana ainda não foram devidamente sistematizados e divulgados às populações vulneráveis, incluindo os trabalhadores expostos. Seus efeitos nocivos têm sido desconsiderados tanto no agravamento das viroses, quanto no surgimento de outras patologias como: alergias, imunotoxicidade, câncer, distúrbios hormonais, neurotoxicidade, dentre outras $^{11}$.

\section{Conclusão}

Nesta revisão sistemática, foram encontrados resultados que evidênciam o efeito mutagênico do malathion utilizado como formulação comercial, ou seja, contendo seus análogos malaoxon e isomalathion, e sua capacidade de promover alterações no DNA in vivo. Dessa forma, uma vez que tais alterações possam atingir regiões de oncogenes ou supressores de tumores no DNA, processos neoplásicos podem ser desencadeados, tanto em animais como em humanos expostos.

Os resultados dos estudos in vitro, tanto em culturas celulares de animais como de seres humanos expostos ao malathion, evidenciaram danos ao DNA, alterações cromossômicas, trocas de cromátides-irmãs e micronúcleos. Os estudos experimentais in vivo mostraram evidências suficientes quanto ao potencial do agrotóxico tanto na indução de danos genéticos como na indução de neoplasias em mamíferos. Os estudos epidemiológicos evidenciaram associações positivas estatisticamente significantes para câncer de tireóide, de mama, e ovariano em mulheres na menopausa.

$\mathrm{O}$ efeito carcinogênico desse agrotóxico e suas implicações ao ambiente e aos seres humanos devem ser consideradas, particularmente no âmbito do controle de arboviroses. 


\section{Colaboradores}

PL Bastos participou da coleta e análise dos dados, na concepção e redação final do artigo. AFT Lima participou da coleta e análise dos dados e revisão do texto final. AM Gurgel participou na concepção do artigo, na análise dos dados e na revisão do texto final. IGD Gurgel participou da análise dos dados, na concepção, redação e revisão final do artigo.

\section{Referências}

1. Ojha A, Srivastava N. In vitro studies on organophosphate pesticides induced oxidative DNA damage in rat lymphocytes. Mutat Res Genet Toxicol Environ Mutagen 2014; 721:10-17.

2. Ecobichon DJ. Pesticide use in developing countries. Toxicology 2001; 160(1-3):27-33.

3. Edwards FL, Tchounwou PB. Environmental toxicology and health effects associated with methyl parathion exposure - a scientific review. Int J Environ Res Public Health 2005; 2(3):430-441.

4. Ecobichon DJ, Joy RM. Pesticides and neurological diseases. In: Casarett LJ, Doull J, organizadores Toxicology: the basic science of poisons. $4^{\mathrm{a}} \mathrm{ed}$. Boca Raton, CRC Press; 1991. p. 565-622.

5. Cavaliere MJ, Calore EE, Perez NM, Puga FR. Miotoxicidade por organofosforados. Rev Saúde Publica 1996; 30(3):267-272.

6. Repetto R, Baliga SS. Review article: Pesticide and immunosuppression: the risks to public heath. Health Policy Plan 1997; 12(2):97-106.

7. Koifman S, Koifman RJ, Meyer A. Human reproductive system disturbances and pesticide exposure in Brazil. Cad Saude Publica 2002; 18(2):435-445.

8. Peres F, Moreira JC, Dubois GS. Agrotóxicos, saúde e ambiente: uma introdução ao tema. In: Peres F, Moreira JC, organizadores. É veneno ou é remédio? Agrotóxicos, saúde e ambiente. Rio de Janeiro: Fiocruz; 2003. p. 21-41.

9. Brasil. Ministério da Saúde (MS). Secretaria de Vigilância em Saúde. Monitoramento dos casos de dengue e febre de chikungunya até a Semana Epidemiológica 48, 2015. Bol Epidemiol 2015; 46(14):1-9.

10. Brasil. Ministério da Saúde (MS). Recomendações sobre o uso de Malathion Emulsão Aquosa - EA 44\% para $o$ controle de Aedes aegypti em aplicações espaciais a Ultra Baixo Volume (UBV) [Internet]. 2014 [acessado 2017 Mar 28]. Disponível em: http://portalarquivos.saude.gov.br/images/pdf/2014/setembro/02/ Recomenda----es-para-o-uso-de-malathion-EW.pdf

11. Associação Brasileira de Saúde Coletiva (Abrasco). Nota técnica e carta aberta à população: $M i$ crocefalia e doenças vetoriais relacionadas ao Aedes aegypti - os perigos das abordagens com larvicidas e nebulização química - fumacê. GT Saúde e Ambiente [Internet]. Abrasco; 2016 [acessado 2016 Jul 10] Disponível em: https://www.abrasco.org.br/ site/noticias/institucional/nota-tecnica-sobre-microcefalia-e-doencas-vetoriais-relacionadas-ao-aedes-aegypti-os-perigos-das-abordagens-com-larvicidas-e-nebulizacoes-quimicas-fumace/15929/

12. Mills PK, Yang R. Breast cancer risk in hispanic agricultural workers in California. Int J Occup Environ Health 2005; 11(2):123-131.

13. Flessel P, Quintana PJ, Hooper K. Genetic toxicity of malathion: a review. Environ Mol Mutagen 1993; 22:717.

14. Thompson CW, Frick JA, Natke BC, Hansen LK. Preparation, analysis, and anticholinesterase properties of O,O-dimethyl phosphorothioate isomerides. Chem Res Toxicol 1989; 2:386-391.

15. Iyer V, Parmar BS. The isomalathion problem - a review. Int J Tropic Agric 1984; 11:199-204. 
16. Moore PD, Yedjou CG, Tchounwou PB. Malathion-Induced Oxidative Stress, Cytotoxicity and Genotoxicity in Human Liver Carcinoma $\left(\mathrm{HepG}_{2}\right)$ Cells. Environ Toxicol 2010; 25(3):221-226.

17. Moore PD, Patlolla AK, Tchounwou PB. Cytogenetic evaluation of malathion-induced toxicity in Sprague-Dawley rats. Mutat Res 2011; 725(1-2):78-82.

18. Ojha A, Gupta YK. Evaluation of genotoxic potential of commonly used organophosphate pesticides in peripheral blood lymphocytes of rats. Hum Exp Toxicol 2015; 34(4):390-400.

19. International Agency for Research on Cancer (IARC). Malathion. IARC Monogr Eval Carcinog Risk Chem Hum 2016; 112:1-454.

20. Pavão $\mathrm{AC}$, Leão $\mathrm{M}$. Riscos da carcinogênese química no controle do Aedes aegypti. In: Augusto LGS, Carneiro RM, Martins PH, organizadores. Abordagem ecossistêmica em Saúde: Ensaios para o controle de dengue. Recife: Editora Universitária; 2005. p. 213-225.

21. International Agency for Research on Cancer (IARC). Miscellaneous pesticides. Malathion. IARC Monogr Eval Carcinog Risk Chem Hum 1983; 30:1-424.

22. International Agency for Research on Cancer (IARC). Overall evaluations of carcinogenicity: an updating of IARC Monographs volumes 1 to 42. IARC Monogr Eval Carcinog Risks Hum Suppl 1987; 7:1-440.

23. Josse R, Sharanek A, Savary CC, Guillouzo A. Impact of isomalathion on malathion cytotoxicity and genotoxicity in human HepaRG cells. Chem Biol Interact 2014; 209:68-76.

24. Anjum R, Malik A. Evaluation of mutagenicity of wastewater in the vicinity of pesticide industry. Environ Toxicol Pharmacol 2013; 35:284-291.

25. Galántai R, Em dy-Kiss B, Somosy Z, Bognár G, Horváth $\mathrm{G}$, Forgács Z, Gachályi A, Szilasi M. Does malaoxon play a role in the geno- and cytotoxic effects of malathion on human choriocarcinoma cells? J Environ Sci Health B 2011; 46:773-779.

26. Moore PD, Patlolla AK, Tchounwou PB. Cytogenetic evaluation of malathion-induced toxicity in Sprague-Dawley rats. Mutat Res Genet Toxicol Environ Mutagen 2011; 725:78-82.

27. Jose S, Jayesh P, Mohandas A, Philip R, Bright Sigh I.S. Application of primary haemocyte culture of Penaeus monodon in the assessment of cytotoxicity and genotoxicity of heavy metals and pesticides. Mar Environ Res 2011; 71:169-177.

28. Moore PD, Yedjou CG, Tchounwou PB. Malathion-Induced Oxidative Stress, Cytotoxicity, and Genotoxicity in Human Liver Carcinoma $\left(\mathrm{HepG}_{2}\right)$ Cells. Environ Toxicol 2010; 25:221-226.

29. Calaf GM, Echiburu-Chau C, Roy D. Organophosphorous pesticides and estrogen induce transformation of breast cells affecting p53 and c-Ha-ras genes. Int J Oncol 2009; 35:1061-1068.

30. Calaf GM, Roy D. Cancer genes induced by malathion and parathion in the presence of estrogen in breast cells. Int J Mol Med 2008; 21:261-268.

31. Błasiak J, Kowalik J. Protective Action of Sodium Ascorbate against the DNA-Damaging Effect of Malaoxon. Pestic Biochem Physiol 1999; 65:110-118.
32. Błasiak J, Jałoszynski P, Trzeciak A, Szyfter K. In vitro studies on the genotoxicity of the organophosphorus insecticide malathion and its two analogues. Mutat Res 1999; 445:275-283.

33. Błasiak J, Trzeciak A. Single Cell Gel Electrophoresis (Comet Assay) as a Tool for Environmental Biomonitoring. An Example of Pesticides. Pol J Environ Stud 1998; 7(4):189-194.

34. Pluth JM, O’Neill JP, Nicklas JA, Albertini RJ. Molecular bases of hprt mutations in malathion-treated human T-lymphocytes. Mutat Res 1998; 397:137-148.

35. Hour TC, Chen L, Lin JK. Comparative investigation on the mutagenicities of organophosphate, phthalimide, pyrethroid and carbamate insecticides by the Ames and lactam tests. Mutagenesis 1998; 13(2):157166.

36. Gupta SC, Sahai R, Gupta N. Cytogenetic Effects of Malathion on Buffalo Blood Culture. Asian-Australas J Anim Sci 1996; 9(4):449-454.

37. Balaji M, Sasikala K. Cytogenetic effect of malathion in in vitro culture of human peripheral blood. Mutat Res 1993; 301:13-17.

38. Johnson BT. An Evaluation of a Genotoxicity Assay With Liver S9 for Activation and Luminescent Bacteria for Detection. Environ Toxicol Chem 1992; 11:473480.

39. Garry VF, Nelson RL, Griffith J, Harkins M. Preparation for Human Study of Pesticide Applicators: Sister Chromatid Exchanges and Chromosome Aberrations in Cultured Human Lymphocytes Exposed to Selected Fumigants. Teratog Carcinog Mutagen 1990; 10:21-29.

40. Pednekar MD, Gandhi SR, Netrawali MS. Evaluation of Mutagenic Activities of Endosulfan, Phosalone, Malathion, and Permethrin, Before and After Metabolic Activation, in the Ames Salmonella Test. Environ Contam Toxicol 1987; 38:925-933.

41. Houk VS, DeMarini DM. Induction of prophage lambda by chlorinated pesticides. Mutat Res 1987 182:193-201.

42. Wiaderkiewicz R, Walter Z, Reimschussel W. Sites of Methylation of DNA Bases by the Action of Organophosphorus Insecticides In Vitro. Acta Biochim Pol 1986; 33(2):73-85.

43. Ma TH, Anderson VA, Harris MM, Bare JL. Tradescantia-Micronucleus (Trad-MCN) Test on the Genotoxicity of Malathion. Environ Mutagen 1983; 5:127137.

44. Gilot-Delhalle J, Colizzi A, Moutschen J, MoutschenDahmen M. Mutagenicity of some organophosphorus compounds at the ade6 locus of Schizosaccharomyces pombe. Mutat Res 1983; 117:139-148.

45. Tretyakova NY, Groehler IV A, Ji S. DNA-Protein Cross-links: Formation, Structural Identities, and Biological Outcomes. Acc Chem Res 2016; 48(6):16311644.

46. Bedor CNG. Estudo do potencial carcinogênico dos agrotóxicos empregados na fruticultura e sua implicação para a vigilância da saúde [tese]. Recife: Centro de Pesquisas Aggeu Magalhães; 2008.

47. Flessel P, Quintana PJ, Hooper K. Genetic toxicity of malathion: a review. Environ Mol Mutagen 1993; 22(1):7-17. 
48. Hussain R, Mahmood F, Khan A. Genotoxic and Pathological Effects of Malathion in Male Japanese Quail (Coturnix japonica). Pak J Agri Sci 2015; 52(4):1149-1156.

49. Omran OM, Omer OH. The effects of alpha-lipoic acid on breast of female albino rats exposed to malathion Histopathological and immunohistochemical study. Pathol Res Pract 2015; 211:462-469.

50. Selmi S, El-Fazaa S, Gharbi N. Oxidative stress and alteration of biochemical markers in liver and kidney by malathion in rat pups. Toxicol Ind Health 2015; 31(9):783-788.

51. Calaf GM, Echiburú-Chau C. Synergistic effect of malathion and estrogen on mammary gland carcinogenesis. Oncol Rep 2012; 28:640-646.

52. Alfaro-Lira S, Pizarro-Ortiz M, Calaf GM. Malignant Transformation of Rat Kidney Induced by Environmental Substances and Estrogen. Int J Environ Res Public Health 2012; 9:1630-1648.

53. Giri A, Yadav SS, Giri S, Sharma GD. Effect of predator stress and malathion on tadpoles of Indian skittering frog. Aquat Toxicol 2012; 106-107:157-163.

54. Giri A, Giri S, Sharma GD. Malathion and Fenvalerate Induce Micronuclei in Mouse Bone Marrow Cells. Environ Mol Mutagen 2011; 52:607-613.

55. Calaf GM, Garrido F. Catechol estrogens as biomarkers for mammary gland cancer. Int J Oncol 2011; 39:177-183.

56. Bernhardt V, D'Souza J, Shantaram M. In vivo genetic damage induced by commercial Malathion and the antigenotoxic role of Withania somnifera. Int J Integr Biol 2011; 11(2):78.

57. Echiburú-Chau C, Calaf GM. Rat lung cancer induced by malathion and estrogen. Int J Oncol 2008; 33:603611.

58. R'eus GZ, Valvassori SS, Nuernberg H, Comim CM, Stringari RB, Padilha PT, Leffa DD, Tavares P, Dagostim G, Paula MMS, Andrade VM, Quevedo J. DNA damage after acute and chronic treatment with malathion in rats. J Agric Food Chem 2008; 56:7560-7565.

59. Giria S, Prasad SB, Giri A, Sharma GD. Genotoxic effects of malathion: an organophosphorus insecticide, using three mammalian bioassays in vivo. Mutat Res 2002; 514:223-231.

60. Cabello G, Valenzuela M, Vilaxa A, Durán V, Rudolph I, Hrepic N, Calaf G. A Rat Mammary Tumor Model Induced by the Organophosphorous Pesticides Parathion and Malathion, Possibly through Acetylcholinesterase Inhibition. Environ Health Perspect 2001; 109(5):471-479.

61. Amer SM, Fahmy MA, Donya SM. Cytogenetic Effect of Some Insecticides in Mouse Spleen. J Appl Toxicol 1996; 16(1):1-3.

62. Fourernan P, Mason JM, Valencia R, Zirnmering S. Chemical Mutagenesis Testing in Drosophila. X. Results of 70 Coded Chemicals Tested for the National Toxicology Program. Environ Mol Mutagen 1994; 23:208-227.

63. Hoshiya T, Hasegawa R, Hakoi K, Cui L, Ogiso T, Cabral R, Ito N. Enhancement by non-mutagenic pesticides of GST-P positive hepatic foci dlevelopment rat initiated with diethylnitrosamine in the rat. Cancer Lett 1993; 72:59-64.
64. Hasegawa R, Ito N. Liver medium-term bioassay in rats for screening of carcinogens and modifying factors in hepatocarcinogenesis. Fd Chem Toxic 1992; 30(11):979-992.

65. Hoda MQ, Sinha SP. Protective role of ascorbic acid and vitamin B-complex against pesticide-induced clastogeny in bone marrow cells of mice. Internat J Vit Nutr Res 1991; 61:155-158.

66. Velázquez A, Creus A, Xamena N, Marcos R. Lack of mutagenicity of the organophosphorus insecticide malathion in Drosophila melanogaster. Environ Mutagen 1987; 9:343-348.

67. Dzwonkowska A, Hiibner H. Induction of chromosmal aberrations in the Syrian hamster by insecticides tested in vivo. Arch Toxicol 1986; 58:152-156.

68. Degraeve N, Chollet MC, Moutschent J. Mutagenic efficiency of organophosphorus insecticides used in combined treatments. Environ Health Perspect 1985; 60:395-398.

69. Degraeve N, Chollet MC, Moutschen J. Cytogenetic and genetic effects of subehronic treatments with organophosphorus insecticides. Arch Toxicol 1984; 56:66-67.

70. Degraeve N, Chollet MC, Moutschen J. Evaluation of the mutagenic potential of four commercial mixtures of insecticides. Fd Che Toxic 1984; 22(8):683-687.

71. Dulout FN, Pastori MC, Olivero OA. Malathion-induced chromosomal aberrations in bone- marrow cells of mice: dose-response relationships. Mutat Res 1983; 122:163-167.

72. Satoh K, Kitahara A, Soma Y, Inaba Y, Hatayama I, Sato K. Purification, induction, and distribution of placental glutathione transferase; a new marker enzyme for preneoplastic cells in the rat chemical hepatocarcinogenesis. Proc Natl Acad Sci 1985; 82:3964-3968.

73. Pal A, Gin KY-H, Lin AY-C.; Reinhard M. Impacts of emerging organic contaminants on freshwater resources: review of recent occurrences, sources, fate and effects. Sci Total Environ 2010; 408:6062-6069.

74. Diamanti-Kandarakis E, Bourguignon JP, Giudice LC, Hauser R, Prins GS, Soto AM, Zoeller RT, Gore AC. Endocrine-disrupting chemicals: An Endocrine Society scientific statement. Endocr Rev 2009, 30:293-342.

75. Adeel M, Song X, Wang Y, Francis D, Yang Y. Environmental impact of estrogens on human, animal and plant life: A critical review. Environ Int 2017; 99:107119.

76. Andreotti G, Hoppin JA, Hou L, Koutros S, Gadalla SM, Savage SA, Lubin J, Blair A, Hoxha M, Baccarelli A, Sandler D, Alavanja M, Freeman LEB. Pesticide use and relative leukocyte telomere length in the agricultural health study. PLoS ONE 2015; 10(7):e0133382.

77. Arshad M, Siddiqa M, Rashid S, Hashmi I, Awan MA, Ali MA. Biomonitoring of toxic effects of pesticides in occupationally exposed individuals. Saf Health Work 2015; 7:156-160.

78. Lerro, Koutros S, Andreotti G, Friesen MC, Alavanja MC, Blair A, Hoppin JA, Sandler DP, Lubin JH, Ma X, Zhang Y, Freeman LEB. Organophosphate insecticide use and cancer incidence among spouses of pesticide applicators in the Agricultural Health Study. Occup Environ Med 2015; 72:736-744. 
79. Alavanja MCR, Hofmann JN, Lynch CF, Hines CJ, Barry KH, Barker J, Buckman DW, Thomas K, Sandler DP, Hoppin JA, Koutros S, Andreotti G, Lubin JH, Blair A, Freeman LEB. Non-hodgkin lymphoma risk and insecticide, fungicide and fumigant use in the agricultural health study. PLOS ONE 2014; 9(10):e109332.

80. Koutros S, Berndt SI, Barry KH, Andreotti G, Hoppin JA, Sandler DP, Yeager M, Burdett LA, Yuenger J, Alavanja MCR, Freeman LEB. Genetic susceptibility loci, pesticide exposure and prostate cancer risk. PLoS ONE 2013; 8(4):e58195.

81. Cabello G, Valenzuela-Estrada M, Siques P, Brito J, Parra E, Valdivia U, Lavin C, Manríquez A, Ortega A. Relation of breast cancer and malathion aerial spraying in Arica, Chile. Int J Morphol 2013; 31(2):640-645.

82. Kachuri L, Demers PA, Blair A, Spinelli JJ, Pahwa M, McLaughlin JR, Pahwa P, Dosman JA, Harris SA. Multiple pesticide exposures and the risk of multiple myeloma in Canadian men. Int J Cancer 2013; 133:18461858.

83. Koutros S, Freeman LEB, Lubin JH, Heltshe SL, Andreotti G, Barry KH, DellaValle CT, Hoppin JA, Sandler DP, Lynch CF, Blair A, Alavanja MCR. Risk of total and aggressive prostate cancer and pesticide use in the Agricultural Health Study. Am J Epidemiol 2012; 177(1):5974.

84. Pahwa M, Harris SA, Hohenadel K, McLaughlin JR, Spinelli JJ, Pahwa P, Dosman JA and Blair A. Pesticide use, immunologic conditions, and risk of non-Hodgkin lymphoma in Canadian men in six provinces. Int J Cancer 2012; 131:2650-2659.

85. Barry KH, Koutros S, Berndt SI, Andreotti G, Hoppin JA, Sandler DP, Burdette LA, Yeager M, Freeman LEB, Lubin JH, Ma X, Zheng T, Alavanja MCR. Genetic variation in base excision repair pathway genes, pesticide exposure, and prostate cancer risk. Environ Health Perspect 2011; 119(12):1726-1732.

86. Pahwa P, Karunanayake CP, Dosman JA, Spinelli JJ, McLaughlin JR, Cross-Canada Group. Soft-tissue sarcoma and pesticides exposure in men results of a canadian case-control study. J Occup Environ Med 2011; 53(11):1279-1286.

87. Hohenadel K, Harris SA, McLaughlin JR, Spinelli JJ, Pahwa P, Dosman JA, Demers PA, Blair A. Exposure to multiple pesticides and risk of non-hodgkin lymphoma in men from six canadian provinces. Int $J$ Environ Res Public Health 2011; 8:2320-2330.

88. Band PR, Abanto Z, Bert J, Lang B, Fang R, Gallagher RP, Le ND. Prostate cancer risk and exposure to pesticides in british columbia farmers. Prostate 2011; 71:168-183.

89. Andreotti G; Hou L; Freeman LEB; Mahajan R; Koutros S; Coble J; Lubin J; Blair A; Hoppin JA; Alavanja M. Body mass index, agricultural pesticide use, and cancer incidence in the Agricultural Health Study cohort. Cancer Causes Control 2010; 21:1759-1775.

90. Andreotti G, Freeman LEB, Hou L, Coble J, Rusiecki J, Hoppin JA, Silverman DT, Alavanja MCR. Agricultural pesticide use and pancreatic cancer risk in the Agricultural Health Study Cohort. Int J Cancer 2009; 124:24952500.
91. Bonner MR, Coble J, Blair A, Freeman LEB, Hoppin JA, Sandler DP, Alavanja MCR. Malathion exposure and the incidence of cancer in the Agricultural Health Study. Am J Epidemiol 2007; 166(9):1023-103.

92. Zeljezic D, Garaj-Vrhova V. Sister chromatid exchange and proliferative rate index in the longitudinal risk assessment of occupational exposure to pesticides. Chemosphere 2002; 46:295-303.

93. Garaj-Vrhovac V, Zeljezic D. Cytogenetic monitoring of croatian population occupationally exposed to a complex mixture of pesticides. Toxicology 2001; $165: 153-162$

94. McDuffie HH, Pahwa P, McLaughlin JR, Spinelli JJ, Fincham S, Dosman JA, Robson D, Skinnider LF, Choi NW. Non-hodgkin's lymphoma and specific pesticide exposures in men: cross-Canada study of pesticides and health. Cancer Epidemiol Biomarkers Prev 2001; 10:1155-1163.

95. Titenko-Holland N, Windham G, Kolachana P, Reinisch F, Parvatham S, Osorio AM, Smith MT. Genotoxicity of malathion in human lymphocytes assessed using the micronucleus assay in vitro and in vivo: A study of malathion-exposed workers. Mutat Res 1997; 388:85-95.

96. Pluth JM, Nicklas JA, O’Neill JP, Albertini RJ. Increased frequency of specific genomic deletions resulting from in vitro malathion exposure. Cancer Res 1996; 56:2393-2399.

97. Czeizel AE. Phenotypic and cytogenetic studies in self-poisoned patients. Mutat Res 1994; 313:175-181.

98. Cantor KP, Blair A, Everett G, Gibson R, Burmeister LF, Brown LM, Schuman L, Dick FR. Pesticides and other agricultural risk factors for non-hodgkin's lymphoma among men in Iowa and Minnesota. Cancer Res 1992; 52:2447-2455.

99. Rupa DS, Reddy PP, Sreemannarayana K, Reddi OS, Frequency of sister chromatid exchange in peripheral lymphocytes of male pesticide applicators. Environ Mol Mutagen 1991; 18:136-138.

100. Rupa DS, Reddy PP, Reddi OS. Frequencies of chromosomal aberrations in smokers exposed to pesticides in cotton fields. Mutat Res 1989; 222:37-41.

101. Ma H, Zhou Z, Wei S, Liu Z, Pooley KA, Dunning AM, Svenson U, Roos G, Hosgood HD 3rd, Shen M, Wei Q. Shortened telomere length is associated withincreased risk of cancer: a meta-analysis. PLoS One 2011; 6:e20466.

102. Wentzensen IM, Mirabello L, Pfeiffer RM, Savage SA. The association of telomere length and cancer: a meta-analysis. Cancer Epidemiol Biomarkers Prev 2011; 20(6):1238-1250.

103. Kós MI, Hoshino AC, Asmus CIF, Mendonça R, Meyer A. Efeitos da exposição a agrotóxicos sobre o sistema auditivo periférico e central: uma revisão sistemática. Cad Saude Publica 2013; 29(8):1491-1506.

Artigo apresentado em 18/04/2018

Aprovado em 11/10/2018

Versão final apresentada em 13/10/2018 
